\title{
Development of the RAQM2 aerosol chemical transport model and predictions of the Northeast Asian aerosol mass, size, chemistry, and mixing type
}

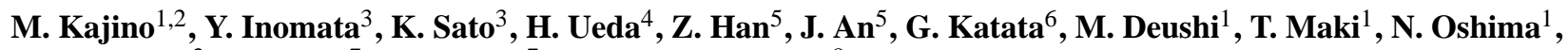 \\ J. Kurokawa ${ }^{3}$, T. Ohara ${ }^{7}$, A. Takami ${ }^{7}$, and S. Hatakeyama ${ }^{8}$ \\ ${ }^{1}$ Meteorological Research Institute, Japan Meteorological Agency, 1-1 Nagamine, Tsukuba 305-0052, Japan \\ ${ }^{2}$ Pacific Northwest National Laboratory, P.O. Box 999 Richland WA 99352, USA \\ ${ }^{3}$ Asia Center for Air Pollution Research, 1182 Sowa, Nishi, Niigata 950-2144, Japan \\ ${ }^{4}$ Toyohashi Institute of Technology, 1-1 Hibarigaoka, Tempaku, Toyohashi 950-2144, Japan \\ ${ }^{5}$ Institute of Atmospheric Physics, Chinese Academy of Sciences, Beijing 100029, China \\ ${ }^{6}$ Japan Atomic Energy Agency, 2-4 Shirakata-shirane, Tokai, Ibaraki 319-1195, Japan \\ ${ }^{7}$ National Institute for Environmental Studies, 16-2 Onogawa, Tsukuba 305-8506, Japan \\ ${ }^{8}$ Tokyo University of Agriculture and Technology, 3-5-8 Saiwaicho, Fuchu, Tokyo 183-8509, Japan \\ Correspondence to: M. Kajino (kajino@mri-jma.go.jp)
}

Received: 18 February 2012 - Published in Atmos. Chem. Phys. Discuss.: 30 May 2012

Revised: 21 September 2012 - Accepted: 3 December 2012 - Published: 17 December 2012

\begin{abstract}
A new aerosol chemical transport model, the Regional Air Quality Model 2 (RAQM2), was developed to simulate the Asian air quality. We implemented a simple version of a triple-moment modal aerosol dynamics model (MADMS) and achieved a completely dynamic (nonequilibrium) solution of a gas-to-particle mass transfer over a wide range of aerosol diameters from $1 \mathrm{~nm}$ to super- $\mu \mathrm{m}$. To consider a variety of atmospheric aerosol properties, a category approach was utilized in which the aerosols were distributed into four categories: particles in the Aitken mode (ATK), soot-free particles in the accumulation mode (ACM), soot aggregates (AGR), and particles in the coarse mode (COR). The aerosol size distribution in each category is characterized by a single mode. The condensation, evaporation, and Brownian coagulations for each mode were solved dynamically. A regional-scale simulation $(\Delta x=60 \mathrm{~km})$ was performed for the entire year of 2006 covering the Northeast Asian region. The modeled $\mathrm{PM}_{1} /$ bulk ratios of the chemical components were consistent with observations, indicating that the simulated aerosol mixing types were consistent with those in nature. The non-sea-salt $\mathrm{SO}_{4}^{2-}$ mixed with ATK $+\mathrm{ACM}$ was the largest at Hedo in summer, whereas the $\mathrm{SO}_{4}^{2-}$ was substantially mixed with AGR in the cold seasons.
\end{abstract}

Ninety-eight percent of the modeled $\mathrm{NO}_{3}^{-}$was mixed with sea salt at Hedo, whereas $53.7 \%$ of the $\mathrm{NO}_{3}^{-}$was mixed with sea salt at Gosan, which is located upwind toward the Asian continent. The condensation of $\mathrm{HNO}_{3}$ onto sea salt particles during transport over the ocean accounts for the difference in the $\mathrm{NO}_{3}^{-}$mixing type at the two sites. Because the aerosol mixing type alters the optical properties and cloud condensation nuclei activity, its accurate prediction and evaluation are indispensable for aerosol-cloud-radiation interaction studies.

\section{Introduction}

Atmospheric trace gases and aerosols have various detrimental effects on ecosystems and human health. Because their emission, secondary formation, transport and deposition mechanisms are highly complex and still poorly understood, a great number of studies on the development and application of air quality modeling are ongoing. Recently, Jacobson and Ginnebaugh (2010) developed a globalthrough-urban nested three-dimensional air pollution model that implements a large explicit photochemical mechanism with 4675 gases and 13626 tropospheric and stratospheric 
chemical reactions. The mechanism also includes one internally mixed aerosol and three hydrometeor categories that are size and chemistry resolved (17 components $\times$ 14 size bins for aerosols, 18 components $\times 30$ size bins for cloud/precipitation liquid, cloud/precipitation ice, and cloud/precipitation graupel). On the other hand, there is still a great demand for computationally efficient models for long-term integration with higher grid resolutions. For example, the Community Multiscale Air Quality (CMAQ) model (Byun and Schere, 2006) was extensively used worldwide and was continually updated for more than $10 \mathrm{yr}$ (Foley et al., 2010) until the current version 5.0.1 (released in July 2012).

The Asian air quality is highly complex because it covers the tropics to the polar zones with large amounts of anthropogenic air pollutants and natural Asian dust particles along with other natural species. The Regional Air Quality Model (RAQM) was developed at the Acid Deposition and Oxidant Research Center (currently named the Asia Center for Air Pollution Research), which focuses on such Asian air quality problems (An et al., 2002; Han, 2007). The model has been used for various air pollution studies in Asia, such as studies of high oxidant, massive dust transport and volcanic sulfur episodes, and substantial modifications have been made upon comparing and evaluating with extensive long-term monitoring data (An et al., 2002, 2003; Han, 2007; Han et al., 2004, 2005, 2006; Kajino et al., 2004, 2005) and with other models (Carmichael et al., 2008 and references therein). However, an aerosol dynamics module was not implemented in RAQM, and thermodynamic equilibrium was assumed for the gasaerosol partitioning of semi-volatile inorganic components, such as sulfate, nitrate and ammonium.

To simulate the evolutionary processes of microscale aerosol properties such as chemical compositions, size distribution and mixing state, we implemented a simple version of a new modal-moment aerosol dynamics model (Kajino, 2011; Kajino and Kondo, 2011) that enables the nonequilibrium calculation of gas-to-particle mass transfer over a wide range of aerosol diameters from $1 \mathrm{~nm}$ to supermicrometer particles. We also implemented six important parameterizations relating to aerosol dynamics: (1) new particle formation, (2) cloud condensation nuclei (CCN) activation, (3) ice nuclei (IN) activation, (4) an explicit grid-scale cloud microphysical module, (5) dry deposition, and (6) sub-gridscale convection and scavenging.

The new model is referred to as RAQM2. In Sect. 2, a unique aerosol dynamics module with the above parameterizations is described in detail. The model results are evaluated using the Acid Deposition Monitoring Network in East Asia (EANET) and the Cape Hedo Atmosphere and Aerosol Monitoring Station (CHAAMS) observation data described in Sect. 3 and discussion is made for changes in the aerosol mixing types during the long-range transport in Sect. 4. The major findings are summarized in Sect. 5 .

\section{Model description}

\subsection{General description of the WRF/RAQM2 framework and parameterizations used in the models}

In this section, a general description of an offline-coupled meteorology - chemical transport framework (WRFV3, Skamarock et al., 2008/RAQM2) is presented; however, because the aerosol dynamics model implemented to RAQM2 is unique, it is described in detail in Sect. 2.2. Table 1 summarizes the list of data and schemes used in the WRF and RAQM2 models.

Figure 1 shows the model domain of WRF and RAQM2 and the locations of the observation sites for the Acid Deposition Monitoring Network in East Asia (EANET) and the Cape Hedo Atmosphere and Aerosol Monitoring Station (CHAAMS). There are horizontally $90 \times 60$ grids with $60 \mathrm{~km}$ grid resolution on a Lambert conformal map projection. There are 28 vertical layers from the ground to $100 \mathrm{hPa}$ for WRF and 13 layers to $10 \mathrm{~km}$ for RAQM2 with terrainfollowing coordinates. The horizontal grid points are common to both WRF and RAQM2, whereas the vertical grid points are different. After the spline vertical interpolation of wind velocity and air density to the RAQM2 levels, the mass balance is not maintained. Thus, the MSCWM mass continuity model (Ishikawa, 1994) is used to reduce the mass divergence due to vertical interpolation to approximately $10^{-5}$ to $10^{-6}\left(\mathrm{~s}^{-1}\right)$. The input/output time interval for WRF-RAQM2 was set to $1 \mathrm{~h}$. For the lateral and upper boundary concentrations of the RAQM2 simulation, the climatological simulation results of monthly $\mathrm{NO}_{\mathrm{x}}, \mathrm{O}_{\mathrm{x}}, \mathrm{CO}$, and volatile organic compound (VOC) concentrations were used using a globalscale stratospheric and tropospheric chemistry climate model (MRI-CCM2; Deushi and Shibata, 2011). The entire simulation period was $1 \mathrm{yr}$, but each simulation was performed separately for each month (as most of the boundary data sets are on a monthly basis), with a spin-up period of 2 weeks for RAQM2. The WRF simulation was performed for a year at once with a spin-up period of 3 days.

RAQM2 incorporates major processes for atmospheric trace species, such as anthropogenic and natural emissions, advection, turbulent diffusion, photochemistry, new particle formation, condensation, evaporation, Brownian coagulation, dry deposition, grid-scale cloud condensation nuclei (CCN) and ice nuclei (IN) activation and subsequent cloud microphysical processes, grid-scale aqueous chemistry in hydrometeors as well as in aerosol water, subgrid-scale convection and wet scavenging (Table 1).

The emission inventory was obtained from the Regional Emission inventory in ASia (REAS) (Ohara et al., 2007), which was extended to the year 2005 (Kurokawa et al., 2009). The emitted species are $\mathrm{NO}_{\mathrm{x}}, \mathrm{SO}_{2}, \mathrm{NH}_{3}, \mathrm{NMVOCs}$ (Non-Methane Volatile Organic Compounds), BC (Black Carbon), and POAs (Primary Organic Aerosols). Because 
Table 1. List of data and schemes used in the WRF and RAQM2 models.

\begin{tabular}{|c|c|}
\hline Scheme & Name/reference \\
\hline \multicolumn{2}{|l|}{ WRF } \\
\hline Initial and boundary conditions, analysis nudging & $\begin{array}{l}\text { National Center for Environmental Prediction (NCEP) final op- } \\
\text { erational global analysis data (available from http://dss.ucar. } \\
\text { edu/datasets/ds083.2) }\end{array}$ \\
\hline Planetary boundary layer & Mellor-Yamada-Janjic (MYJ) model (Janjic, 2002) \\
\hline Grid-scale cloud microphysics parameterization & The six-class scheme WSM6 (Lin et al., 1983) \\
\hline Subgrid-scale cumulus parameterization & Grell and Devenyi (2002) \\
\hline Land surface model & Noah LSM (Chen and Dudhia, 2001) \\
\hline Long-wave radiation & RRTM (Mlawer et al., 1997) \\
\hline Short-wave radiation & Dudhia (1989) \\
\hline \multicolumn{2}{|l|}{ RAQM2 } \\
\hline Boundary condition of $\mathrm{O}_{3}$ and its precursors & MRI-CCM2 (Deushi and Shibata, 2011) climatological value \\
\hline $\begin{array}{l}\text { Emission (anthropogenic, biogenic, open biomass burning, } \\
\text { mineral dust, sea-salt) }\end{array}$ & $\begin{array}{l}\text { REAS (Ohara et al., 2007; Kurokawa et al., 2009), GFED3 } \\
\text { (Giglio et al., 2010), MEGAN2 (Guenther et al., 2006), Asian } \\
\text { dust (Han et al., 2004), Sea-salt (Clarke et al., 2006) }\end{array}$ \\
\hline Advection & MPMAA (Walcek and Aleksic, 1998) \\
\hline J-value & $\begin{array}{l}\text { Madronich (1987) with TOMS O } 3 \text { column data (available from } \\
\text { ftp://toms.gsfc.nasa.gov) }\end{array}$ \\
\hline Gas chemistry & 72 species and 214 reactions (SAPRC99; Carter, 2000) \\
\hline SOA chemistry & Edney et al. (2007) \\
\hline Liquid chemistry & Walcek and Taylor (1986); Carlton et al. ( 2007) \\
\hline New particle formation & Kuang et al. (2008) \\
\hline Aerosol dynamics (condensation, evaporation, coagulation) & This study and MADMS (Kajino, 2011) \\
\hline $\begin{array}{l}\text { Surface gas-aerosol equilibrium of inorganic and organic } \\
\text { compounds }\end{array}$ & $\begin{array}{l}\text { ISORROPIA2 (Fountoukis and Nenes, 2007), } \\
\text { Edney et al. (2007) }\end{array}$ \\
\hline Dry deposition & $\begin{array}{l}\text { This study, Zhang et al. (2001, 2003), and Katata et al. (2008, } \\
\text { 2011) }\end{array}$ \\
\hline $\mathrm{CCN}$ activation & Abdul-Razzak and Ghan (2000) \\
\hline IN activation & Lohmann and Diehl (2010) \\
\hline Grid-scale cloud microphysics & Lin et al. (1983) \\
\hline $\begin{array}{l}\text { Collision of aerosol with grid-scale rain, snow and graupel } \\
\text { droplets }\end{array}$ & This study \\
\hline Sub-grid-scale convection and wet deposition & ACM (Pleim and Chang, 1992) \\
\hline
\end{tabular}

REAS does not provide seasonal variations of the emission flux, we applied simple monthly variations for Chinese emissions (Table 9 of Zhang et al., 2009). The temporal variations of the anthropogenic emission flux are not considered in the current setting. We used the Global Fire Emissions Database (GFED3; Giglio et al., 2010) for open biomass burning emis- sions $\left(\mathrm{NO}_{\mathrm{x}}, \mathrm{SO}_{2}, \mathrm{NMVOCs,} \mathrm{BC}\right.$ and POA) and the Model of Emissions of Gases and Aerosols from Nature (MEGAN2; Guenther et al., 2006) for biogenic emissions (isoprene and terpenes). Clarke et al. (2006) was used for sea salt production and Han et al. (2004) for the dust deflation process. The fractions of crustal elements such as $\mathrm{Na}^{+}, \mathrm{Ca}^{2+}$, 


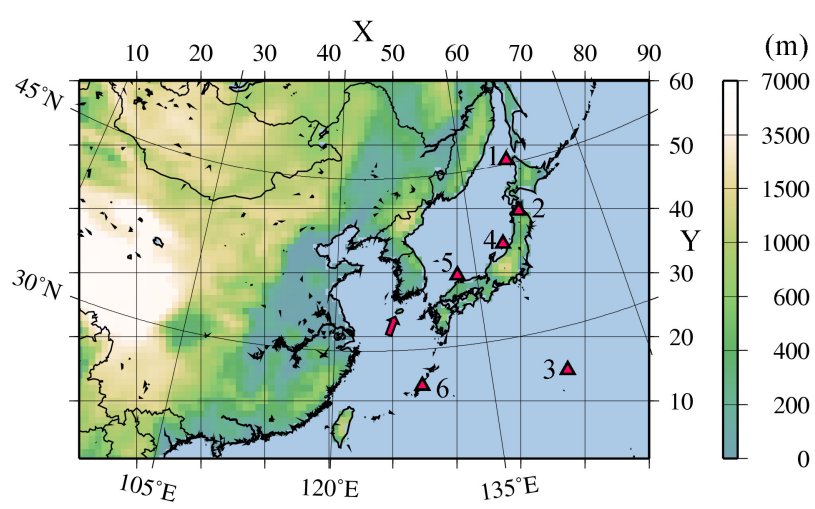

Fig. 1. Model domain showing terrestrial elevation $(\mathrm{m})$ and the six Japanese EANET sites (1. Rishiri, 2. Tappi, 3. Ogasawara, 4. Sado, 5. Oki, 6. Hedo) and the CHAAMS sites (located on the same premises as the EANET Hedo stations). The descriptions of the locations are given in Table 4. An arrow indicates the Gosan site on Jeju Island, Korea.

$\mathrm{Mg}^{2+}$, and $\mathrm{K}^{+}$in sea salt and Asian dust particles are derived from Song and Carmichael (2001). However, using the above combinations, the $\mathrm{PM}_{10}$ and non-sea salt (nss) $\mathrm{Ca}^{2+}$ were overestimated during the dust transport season in spring 2006 in Japan. There have been substantial efforts to adjust the dust emission flux and transport by developing sophisticated physical deflation models (Kang et al., 2011, and references therein) or by applying state-of-the-art data assimilation techniques (e.g., Yumimoto et al., 2008; Sekiyama et al., 2010). Because deducing the accurate dust emission flux was not a focus of this study, we simply uniformly reduced the dust emission to one quarter in time and space and reduced the $\mathrm{Ca}^{2+}$ contents $(6.8 \mathrm{wt} \%)$ in the Asian dust to half (3.4 wt \%) to adjust approximately to both the observed $\mathrm{PM}_{10}$ and the nss- $\mathrm{Ca}^{2+}$ concentration at the Japan EANET stations for 2006. The value of $3.4 \mathrm{wt} \%$ is smaller than that in previous works, such as Song and Carmichael (2001) and Wang et al. (2002), but the value is still plausible when compared with the China-map project data (available at http://www.cgrer. uiowa.edu/EMISSION_DATA/biogeo/Ca-chinamap.gif).

The SAPRC99 mechanism (Carter, 2000) was implemented for gas phase photochemistry along with an additional Secondary Organic Aerosol (SOA) formation mechanism (Edney et al., 2007). However, because the contribution of SOA mass produced by the model was found to be less significant to the East Asian regional-scale simulations and because we focused mainly on the behaviors of the inorganic components, this process was not included in the current study. The aqueous phase chemistry in grid-scale cloud and rain water droplets as well as aerosol water was considered (Walcek and Taylor, 1986; Carlton et al., 2007). The wet scavenging due to subgrid-scale convection was considered using the Asymmetrical Convective Model (Pleim and Chang, 1992), whereas aqueous phase chemistry in convec- tive clouds was not considered. The dry deposition velocities of gaseous species were calculated according to Zhang et al. (2003). The monthly composite MODIS/LAI data processed from MOD15A2 (available from https://lpdaac.usgs. gov/products; Myneni et al., 2002; Yang et al., 2006) were used to obtain realistic values for the surface resistances of the dry deposition velocity. The aerosol dry deposition was calculated using the method of Zhang et al. (2001) with modifications to improve the prediction accuracy, as detailed in Sect. 2.2.8.

\subsection{Formulations of a fully dynamic aerosol module}

The current aerosol module is a three moment bulk dynamics model that conserves number, surface area, and mass concentrations of aerosol populations under the assumption that sizes of aerosols can be represented by unimodal lognormal size distributions (LNSDs). In this section, an aerosol category approach is introduced that presents dynamical and chemical evolutions in the aerosol mass and size distributions due to emissions, new particle formation, condensation, Brownian coagulation, dry deposition, $\mathrm{CCN}$ activation, IN activation, and cloud microphysical processes using a modalmoment dynamics approach.

\subsubsection{Simple version of a triple-moment aerosol module MADMS}

A simple version of the Modal Aerosol Dynamics model for multiple Modes and fractal Shapes (MADMS; Kajino, 2011), a triple-moment aerosol module, was implemented in RAQM2. MADMS can simulate the Brownian coagulation of a couple of modes with very different LNSD parameters and with different mass fractal dimensions $\left(D_{\mathrm{f}}\right)$ of aggregates. In RAQM2, all the particles were simply assumed to be spherical $\left(D_{\mathrm{f}}=3\right)$.

As shown in Table 2, the populations of aerosols were grouped into four categories: (1) particles in the Aitken mode (ATK); (2) soot-free particles in the accumulation mode (ACM); (3) soot aggregates (AGR); and (4) particles in the coarse mode (COR). The ATK category represents an assemblage of aerosols formed by new particle formation and growing through the coagulation and condensation of trace gases and water vapor. The ACM category includes a portion of the ATK aerosols that evolved to be larger than a certain diameter (40 nm in this study) as well as organic compounds and unidentified chemical components, and it excludes BC particles. The AGR category indicates soot aggregates generated through combustion, and it contains BC particles. Therefore, the ATK and ACM are non-light-absorbing particles, whereas AGR are light-absorbing particles. Without separating the AGR category from the others, the evolution of the mixing state of $\mathrm{BC}$ cannot be considered; this alters the absorption of solar radiation and the number of $\mathrm{CCN}$ particles. The COR category includes mechanically produced natural 
Table 2. Aerosol categories and transported variables in the RAQM2 model.

\begin{tabular}{ll|cc|cccccccccc}
\hline $\begin{array}{l}\text { Category } \\
\text { number }\end{array}$ & $\begin{array}{l}\text { Category } \\
\text { name }\end{array}$ & \multicolumn{10}{c|}{ Physical components } & \multicolumn{10}{c}{ Chemical compositions } \\
\hline 1 & $\mathrm{ATK}$ & $M_{0}$ & $M_{2}$ & - & - & - & - & - & $\mathrm{SO}_{4}^{2-}$ & $\mathrm{NH}_{4}^{+}$ & $\mathrm{NO}_{3}^{-}$ & $\mathrm{Cl}^{-}$ & $\mathrm{H}_{2} \mathrm{O}$ \\
2 & $\mathrm{ACM}$ & $M_{0}$ & $M_{2}$ & $\mathrm{UID}$ & - & $\mathrm{OA}$ & - & - & $\mathrm{SO}_{4}^{2-}$ & $\mathrm{NH}_{4}^{+}$ & $\mathrm{NO}_{3}^{-}$ & $\mathrm{Cl}^{-}$ & $\mathrm{H}_{2} \mathrm{O}$ \\
3 & $\mathrm{AGR}$ & $M_{0}$ & $M_{2}$ & $\mathrm{UID}$ & $\mathrm{BC}$ & $\mathrm{OA}$ & - & - & $\mathrm{SO}_{4}^{2-}$ & $\mathrm{NH}_{4}^{+}$ & $\mathrm{NO}_{3}^{-}$ & $\mathrm{Cl}^{-}$ & $\mathrm{H}_{2} \mathrm{O}$ \\
4 & $\mathrm{COR}$ & $M_{0}$ & $M_{2}$ & $\mathrm{UID}$ & $\mathrm{BC}$ & $\mathrm{OA}$ & $\mathrm{DU}$ & $\mathrm{SS}$ & $\mathrm{SO}_{4}^{2-}$ & $\mathrm{NH}_{4}^{+}$ & $\mathrm{NO}_{3}^{-}$ & $\mathrm{Cl}^{-}$ & $\mathrm{H}_{2} \mathrm{O}$ \\
& & $M_{0}^{\mathrm{AGR}}$ & & & & & & & & & & & \\
\hline
\end{tabular}

aerosols such as dust and sea salt particles as well as unidentified components from $\mathrm{PM}_{10}$ emissions.

The aerosol sizes in each category were assumed to be characterized by a unimodal LNSD. Three parameters characterize the LNSD function: the number concentration $N$, the geometric mean diameter $D_{\mathrm{g}}$, and the geometric standard deviation $\sigma_{\mathrm{g}}$. Instead of the three parameters, in modal-moment dynamics modeling, the temporal evolutions of the three moments were solved to characterize the changes in the LNSD. The $k$-th moment is defined as

$M_{k}=\int_{-\infty}^{\infty} D^{k} n(\ln D) \mathrm{d}(\ln D)$

Applying the Gaussian integral formula to Eq. (1) results in

$M_{k}=N D_{\mathrm{g}}^{k} \exp \left[\frac{k^{2}}{2} \ln ^{2} \sigma\right]$

A list of the transported species of each category is shown in Table 2. The zeroth and second moments $\left(M_{0}, M_{2}\right)$ and the mass concentrations of the unidentified components (UIDs), BC, OA (POA plus SOA), dust (DU), sea salt (except chloride) (SS), sulfate, ammonium, nitrate, chloride and water are transported variables. By assuming a constant density for each chemical composition, the $M_{3}$ of each category was determined. More detailed derivations and descriptions of the modal moment approach are given in previous papers (e.g., Binkowski and Shankar, 1995; Whitby and McMurry, 1997; Kajino, 2011). Only the final forms of the equations, the time derivative terms of the moments, are shown in the current paper. How the moments and the LNSD parameters are changed in the process operators are described later in Sect. 2.2.10 and Fig. 2b.

\subsubsection{Intra-modal Brownian coagulation}

The time derivative of moments due to intra-modal coagulation in the free-molecular regime can be expressed as

$$
\begin{aligned}
& \left.\frac{\mathrm{d} M_{0}}{\mathrm{~d} t}\right|_{\mathrm{fm}}=-b K_{\mathrm{fm}}\left[M_{0} M_{0.5}+M_{2} M_{-1.5}+2 M_{1} M_{-0.5}\right] \\
& \left.\frac{\mathrm{d} M_{6}}{\mathrm{~d} t}\right|_{\mathrm{fm}}=2 b K_{\mathrm{fm}}\left[M_{3} M_{3.5}+M_{5} M_{1.5}+2 M_{4} M_{2.5}\right]
\end{aligned}
$$

where $K_{\mathrm{fm}}=\left(\frac{3 k_{\mathrm{B}} T}{\rho_{\mathrm{p}}}\right)^{0.5}, k_{\mathrm{B}}$ is the Boltzmann constant, $T$ is temperature $[\mathrm{K}]$, and $\rho_{\mathrm{p}}$ is the particle density. $b$ is an approximation function of $\sigma$ as

$b(\sigma)=1+1.2 \exp (-2 \sigma)-0.646 \exp \left(-0.35 \sigma^{2}\right)$

The time derivative terms in the near-continuum regime are

$\left.\frac{\mathrm{d} M_{0}}{\mathrm{~d} t}\right|_{\mathrm{nc}}=-K_{\mathrm{nc}}\left[M_{0} M_{0}+M_{1} M_{-1}+A \lambda M_{0} M_{-1}+A \lambda M_{1} M_{-2}\right](5 \mathrm{a})$

$\left.\frac{\mathrm{d} M_{6}}{\mathrm{~d} t}\right|_{\mathrm{nc}}=2 K_{\mathrm{nc}}\left[M_{3} M_{3}+M_{4} M_{2}+A \lambda M_{3} M_{2}+A \lambda M_{4} M_{1}\right]$

where $K_{\mathrm{nc}}=\frac{2 k_{\mathrm{B}} T}{3 \mu}, A=2.492, \mu$ is the viscosity of air, and $\lambda$ is the air molecule mean free path $(\mathrm{cm})$. Finally, the harmonic mean of the time derivative terms in the free-molecular and near-continuum regimes is applied to cover the full size range of aerosols as

$\frac{\mathrm{d} M_{k}}{\mathrm{~d} t}=\left.\frac{\mathrm{d} M_{k}}{\mathrm{~d} t}\right|_{\mathrm{fm}} \times\left.\frac{\mathrm{d} M_{k}}{\mathrm{~d} t}\right|_{\mathrm{nc}} /\left[\left.\frac{\mathrm{d} M_{k}}{\mathrm{~d} t}\right|_{\mathrm{fm}}+\left.\frac{\mathrm{d} M_{k}}{\mathrm{~d} t}\right|_{\mathrm{nc}}\right]$

During the intra-modal coagulation, the third moment proportional to the total volume remains unchanged,

$\frac{\mathrm{d} M_{3}}{\mathrm{~d} t}=0$

\subsubsection{Inter-modal Brownian coagulation}

The rules for the transfer of the three moments and chemical mass concentrations from one mode to another must be predefined for the inter-modal coagulation calculations. These rules are listed in Table 3. Basically, the moments and masses are transferred from smaller/simpler categories into larger/multiple-component categories. Assuming that when a particle in mode $i$ coagulates with a particle in mode $j$, the merged particle goes into mode $j$ (see Table 3), the time derivative terms of the moments in the near-continuum regime can be written as 
(a)

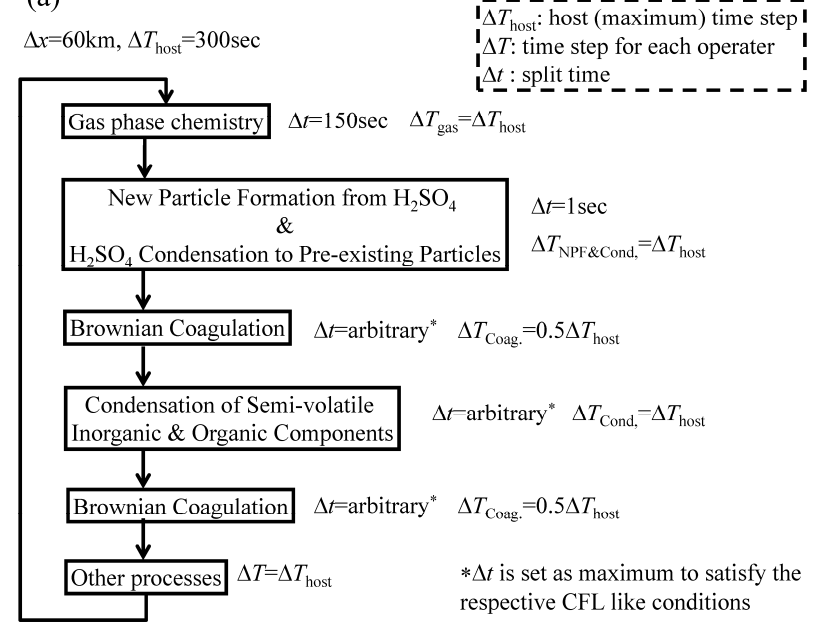

(b)

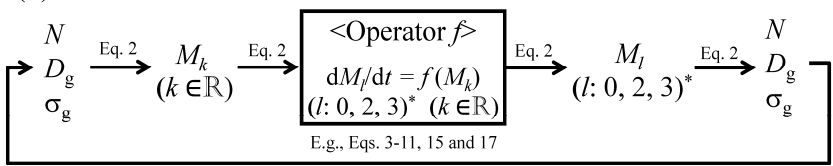

" $(l: 0,3,6)$ for coagulation operator

Fig. 2. Schematic illustration of (a) operator splitting and time splitting for the RAQM2 aerosol dynamics module and (b) changes in moments and LNSD parameters when passing each process operator.

$$
\begin{aligned}
& \left.\frac{\mathrm{d} M_{0}^{i}}{\mathrm{~d} t}\right|_{\mathrm{nc}}=-K_{\mathrm{nc}}\left[2 M_{0}^{i} M_{0}^{j}+M_{1}^{i} M_{-1}^{j}+M_{-1}^{i} M_{1}^{j}+A \lambda M_{0}^{i} M_{-1}^{j}\right. \\
& \left.+A \lambda M_{-1}^{i} M_{0}^{j}+A \lambda M_{1}^{i} M_{-2}^{j}+A \lambda M_{-2}^{i} M_{1}^{j}\right] \\
& \left.\frac{\mathrm{d} M_{3}^{i}}{\mathrm{~d} t}\right|_{\mathrm{nc}}=-K_{\mathrm{nc}}\left[2 M_{3}^{i} M_{0}^{j}+M_{4}^{i} M_{-1}^{j}+M_{2}^{i} M_{1}^{j}+A \lambda M_{3}^{i} M_{-1}^{j}\right. \\
& \left.+A \lambda M_{2}^{i} M_{0}^{j}+A \lambda M_{4}^{i} M_{-2}^{j}+A \lambda M_{1}^{i} M_{1}^{j}\right] \\
& \left.\frac{\mathrm{d} M_{6}^{i}}{\mathrm{~d} t}\right|_{\mathrm{nc}}=-K_{\mathrm{nc}}\left[2 M_{6}^{i} M_{0}^{j}+M_{7}^{i} M_{-1}^{j}+M_{5}^{i} M_{1}^{j}+A \lambda M_{6}^{i} M_{-1}^{j}\right. \\
& \left.+A \lambda M_{5}^{i} M_{0}^{j}+A \lambda M_{7}^{i} M_{-2}^{j}+A \lambda M_{4}^{i} M_{1}^{j}\right] \\
& \left.\frac{\mathrm{d} M_{0}^{j}}{\mathrm{~d} t}\right|_{\mathrm{nc}}=0,\left.\frac{\mathrm{d} M_{3}^{j}}{\mathrm{~d} t}\right|_{\mathrm{nc}}=-\left.\frac{\mathrm{d} M_{3}^{i}}{\mathrm{~d} t}\right|_{\mathrm{nc}} \\
& \left.\frac{\mathrm{d} M_{6}^{j}}{\mathrm{~d} t}\right|_{\mathrm{nc}} ^{\mathrm{nc}}=K_{\mathrm{nc}}\left[2 M_{6}^{i} M_{0}^{j}+M_{7}^{i} M_{-1}^{j}+M_{5}^{i} M_{1}^{j}+A \lambda M_{6}^{i} M_{-1}^{j}\right. \\
& \left.+A \lambda M_{5}^{i} M_{0}^{j}+A \lambda M_{7}^{i} M_{-2}^{j}+A \lambda M_{4}^{i} M_{1}^{j}\right] \\
& +2 K_{\mathrm{nc}}\left[2 M_{3}^{i} M_{3}^{j}+M_{4}^{i} M_{2}^{j}+M_{2}^{i} M_{4}^{j}+A \lambda M_{3}^{i} M_{2}^{j}+A \lambda M_{2}^{i} M_{3}^{j}\right. \\
& \left.+A \lambda M_{4}^{i} M_{1}^{j}+A \lambda M_{1}^{i} M_{4}^{j}\right]
\end{aligned}
$$

where $M_{k}^{i}$ indicates the $k$-th moment of mode $i$. In the freemolecular regime, the equations can be written as
Table 3. Rules for transfer of the three moments and chemical mass concentrations from one category to another due to inter-category coagulation and mode merging.

\begin{tabular}{ll}
\hline Rule Number & \multicolumn{2}{l}{ Rule } \\
\hline \multicolumn{2}{l}{ Inter-category } \\
\hline 1 & 1.ATK $+2 . \mathrm{ACM} \rightarrow 2 . \mathrm{ACM}$ \\
2 & $1 . \mathrm{ATK}+3 . \mathrm{AGR} \rightarrow 3 . \mathrm{AGR}$ \\
3 & $1 . \mathrm{ATK}+4 . \mathrm{COR} \rightarrow 4 . \mathrm{COR}$ \\
4 & $2 . \mathrm{ACM}+3 . \mathrm{AGR} \rightarrow 3 . \mathrm{AGR}$ \\
5 & $2 . \mathrm{ACM}+4 . \mathrm{COR} \rightarrow 4 . \mathrm{COR}$ \\
6 & $3 . \mathrm{AGR}+4 . \mathrm{COR} \rightarrow 4 . \mathrm{COR}$ \\
\hline Mode Merging & \\
\hline 7 & (swelling) $1 . \mathrm{ATK} \rightarrow 2 . \mathrm{ACM}$ \\
8 & (shrinking) $2 . \mathrm{ACM} \rightarrow 1 . \mathrm{ATK}$ \\
\hline
\end{tabular}

$$
\begin{aligned}
& \left.\frac{\mathrm{d} M_{0}^{i}}{\mathrm{~d} t}\right|_{\mathrm{fm}}=-b K_{\mathrm{fm}}\left[M_{0}^{i} M_{0.5}^{j}+M_{0.5}^{i} M_{0}^{j}+M_{2}^{i} M_{-1.5}^{j}\right. \\
& \left.\quad+M_{-1.5}^{i} M_{2}^{j}+M_{1}^{i} M_{-0.5}^{j}+M_{-0.5}^{i} M_{1}^{j}\right] \\
& \left.\frac{\mathrm{d} M_{3}^{i}}{\mathrm{~d} t}\right|_{\mathrm{fm}}=-b K_{\mathrm{fm}}\left[M_{3}^{i} M_{0.5}^{j}+M_{3.5}^{i} M_{0}^{j}+M_{5}^{i} M_{-1.5}^{j}\right. \\
& \left.\quad+M_{1.5}^{i} M_{2}^{j}+M_{4}^{i} M_{-0.5}^{j}+M_{2.5}^{i} M_{1}^{j}\right] \\
& \frac{\left.\mathrm{d} M_{6}^{i}\right|_{\mathrm{fm}}=-b K_{\mathrm{fm}}\left[M_{6}^{i} M_{0.5}^{j}+M_{6.5}^{i} M_{0}^{j}+M_{8}^{i} M_{-1.5}^{j}\right.}{\left.\quad+M_{4.5}^{i} M_{2}^{j}+M_{7}^{i} M_{-0.5}^{j}+M_{5.5}^{i} M_{1}^{j}\right]} \\
& \left.\frac{\mathrm{d} M_{0}^{j}}{\mathrm{~d} t}\right|_{\mathrm{fm}}=0,\left.\frac{\mathrm{d} M_{3}^{j}}{\mathrm{~d} t}\right|_{\mathrm{fm}}=-\left.\frac{\mathrm{d} M_{3}^{i}}{\mathrm{~d} t}\right|_{\mathrm{fm}}=b K_{\mathrm{fm}}\left[M_{6}^{i} M_{0.5}^{j}+M_{6.5}^{i} M_{0}^{j}+M_{8}^{i} M_{-1.5}^{j}\right. \\
& \left.\quad+M_{4.5}^{i} M_{2}^{j}+M_{7}^{i} M_{-0.5}^{j}+M_{5.5}^{i} M_{1}^{j}\right] \\
& +2 b K_{\mathrm{fm}}\left[M_{3}^{i} M_{3.5}^{j}+M_{3.5}^{i} M_{3}^{j}+M_{5}^{i} M_{1.5}^{j}+M_{1.5}^{i} M_{5}^{j}\right. \\
& \left.+M_{4}^{i} M_{2.5}^{j}+M_{2.5}^{i} M_{4}^{j}\right]
\end{aligned}
$$

where the approximation function $b$ newly proposed by Kajino (2011), is

$$
\begin{aligned}
& b=1+1.2 \gamma \exp \left[-2 \frac{\sigma_{i}+\alpha \sigma_{j}}{1+\alpha}\right]-0.646 \gamma \exp \left[-0.35 \frac{\sigma_{i}^{2}+\alpha \sigma_{j}^{2}}{1+\alpha}\right] \\
& \gamma=\left[1-\frac{\sqrt{1+\alpha^{3}}}{1+\sqrt{\alpha^{3}}}\right] /\left[1-\frac{1}{\sqrt{2}}\right], \alpha=\frac{D_{\mathrm{g} j}}{D_{\mathrm{g} i}}
\end{aligned}
$$

The harmonic mean of the time derivative terms (Eq. 6) is applied to cover the full size range.

\subsubsection{Number concentration of soot collided to coarse mode particles}

Soot particles sometimes form internal mixtures with coarse mode particles such as dust and sea salt particles, and such 
mixtures alter optical properties of the coarse mode particles significantly and contribute to atmospheric solar heating and surface dimming (Clarke et al., 2004; Zhu et al., 2007; Guazzotti et al., 2001). Such mixtures can be predicted in the RAQM2 model as BC mass and $M_{0}^{\mathrm{AGR}}$ number concentrations in the COR category (Table 2). $M_{0}^{\mathrm{AGR}}$ indicates the number concentration of soot particles (AGR) that collided with COR particles and is calculated as

$\frac{\mathrm{d} M_{0}^{\mathrm{AGR}}}{\mathrm{d} t}=\left.\frac{\mathrm{d} M_{0}}{\mathrm{~d} t}\right|_{\text {coag }} ^{\mathrm{COR}-\mathrm{AGR}}$

$M_{0}^{\text {AGR }}$ exceeds the $M_{0}$ of COR because $M_{0}^{\text {AGR }}$ does not indicate the number of COR particles internally mixed with soot but indicates the number of times each AGR particle hits COR particles. The Brownian coagulation theory assumes that the coalescence efficiency is unity, which may not be true for the atmospheric aerosols. The efficiency of the bouncing/sticking of colliding atmospheric particles should be formulated.

\subsubsection{Condensation}

The zeroth moment $M_{0}(=N)$ remains constant during the condensation process.

$\frac{\mathrm{d} M_{0}}{\mathrm{~d} t}=0$

The condensational growth of the particle mass $M$ of each mode can be expressed as

$\frac{\mathrm{d} M}{\mathrm{~d} t}=\int \frac{m_{\mathrm{w}, \mathrm{p}}}{m_{\mathrm{w}, \mathrm{g}}}\left(c_{\infty}-c_{\mathrm{s}}\right) \psi\left(d_{\mathrm{p}}\right) n\left(d_{\mathrm{p}}\right) \mathrm{d} d_{\mathrm{p}}$

where $m_{\mathrm{w}, \mathrm{p}}$ and $m_{\mathrm{w}, \mathrm{g}}$ represent the molecular weights of the semi-volatile components in the particle and gas phases, respectively, and $c_{\infty}$ and $c_{\mathrm{S}}$ are the gas phase concentrations in the bulk phase (near the aerosol surface) and on the aerosol surface, respectively. The ${ }_{\mathrm{s}}^{\psi}$ are different in the freemolecular and the near continuum regimes and can be written as

$\psi^{\mathrm{fm}}\left(d_{\mathrm{p}}\right)=\frac{\pi \alpha \bar{c}}{4} d_{\mathrm{p}}^{2}$

and

$\psi^{\mathrm{co}}\left(d_{\mathrm{p}}\right)=2 \pi D_{\mathrm{v}} d_{\mathrm{p}}$

respectively, where $\alpha$ is a mass accommodation coefficient assumed constant as $0.1, \bar{c}$ is the mean velocity of the gas molecules, and $D_{\mathrm{v}}$ is the molecular diffusion coefficient. Using the harmonic mean approach to cover the two regimes, the time derivative term of arbitrary moments due to condensation can be rewritten as

$\frac{\mathrm{d} M_{k}}{\mathrm{~d} t}=\frac{1}{\rho_{\mathrm{p}}} \frac{m_{\mathrm{w}, \mathrm{p}}}{m_{\mathrm{w}, \mathrm{g}}}\left(c_{\infty}-c_{\mathrm{s}}\right)\left|\frac{k \alpha \bar{c}}{2} M_{k-1}, 4 k D_{\mathrm{v}} M_{k-2}\right|_{\mathrm{harm}}$ where $|A, B|_{\text {harm }}$ indicates the harmonic mean of $A$ and $B$ and, thus, $A B /(A+B)$. The condensational growth of mass is expressed as

$\frac{\mathrm{d} M}{\mathrm{~d} t}=\frac{\pi \rho_{\mathrm{p}}}{6} \frac{\mathrm{d} M_{3}}{\mathrm{~d} t}$

To obtain the gas phase concentrations on the aerosol surface $c_{\mathrm{s}}$, which is thermodynamically equilibrated, ISORROPIA II (Fountoukis and Nenes, 2007) and Edney et al. (2007) are used for semi-volatile inorganic and organic compounds, respectively.

\subsubsection{Simultaneous solution of nucleation, condensation and mode merging}

RAQM2 achieved a completely dynamic (non-equilibrium) solution of a gas-to-particle mass transfer over a wide range of aerosol diameters from $1 \mathrm{~nm}$ to super-micrometer sizes. The new particle formation (NPF) process is, however, not dynamically solved but parameterized, which is inevitable for the time and spatial scales of the simulation. Recently, numerous NPF parameterizations have been proposed based on laboratory experiments, theoretical and molecular dynamics calculations, and nanoparticle observations (Kulmala and Kerminen, 2008; Hirsikko et al., 2011). However, numerous uncertainties and discrepancies remain among the parameterizations (Zhang et al., 2010). Therefore, we used the parameterizations based on several observations in diverse atmospheric locations (Kuang et al., 2008) to obtain the plausible nucleation rates for realistic conditions.

To solve the condensation onto the pre-existing particles and the nucleation of sulfuric acid gas, the operator- and time-splitting methods were applied. The nucleation and condensation processes were solved simultaneously using the short split time step $(\Delta t)$ of $1 \mathrm{~s}$ with an explicit method (forward in time) (see Sect. 2.2.9 and Fig. 2a). We found that a 1-s time step was sufficient to yield an accurate nucleation rate under the realistic conditions of sulfuric acid gas up to $10^{8}$ molecules $\left(\mathrm{cm}^{-3}\right)$ and aerosol number concentrations from $10^{2}$ to $10^{6}\left(\mathrm{~cm}^{-3}\right)$ using the Kuang et al. (2008) parameterization. When nucleation occurs, the number of new particles produced within $1 \mathrm{se}$, with a $D_{\mathrm{g}}$ and $\sigma$ of $1 \mathrm{~nm}$ and unity, respectively, were entered in the ATK category. Because the ATK particles swelled rapidly due to condensation and Brownian coagulations, the aerosols were merged into the larger particle category ACM, as shown in Table 3. The portion of the $k$-th moment larger than a criteria diameter $D_{\mathrm{c}}$ were readily calculated using the error function $\operatorname{erf}(x)$ as

$$
\begin{aligned}
{\left[M_{k}\right]_{D_{\mathrm{c}}} } & =\int_{\ln D_{\mathrm{c}}}^{\infty} D^{k} n(\ln D) \mathrm{d} \ln D \\
& =\frac{M_{k}}{2}\left[1-\operatorname{erf}\left(\frac{\ln D_{\mathrm{c}}-\ln D_{\mathrm{g}}-k \ln ^{2} \sigma}{\sqrt{2} \ln \sigma}\right)\right]
\end{aligned}
$$


The portion of mass is identical to that of the third moment. Each moment and each mass of the chemical compositions in ATK exceeding $D_{\mathrm{c}}$ (set as $40 \mathrm{~nm}$ in the study) was merged into the ACM category using Eq. (17) and vice versa: when the shrinking of the ACM occurs, the portion of the moments and mass smaller than $40 \mathrm{~nm}$ are merged into ATK (Table 3).

\subsubsection{Grid-scale and sub-grid-scale wet deposition}

For the grid-scale wet deposition, the $\mathrm{CCN}$ activation and subsequent cloud microphysical processes were parameterized using Abdul-Razzak and Ghan (2000) and WSM6 (Lin et al., 1983). When the Abdul-Razzak and Ghan (2000) parameterization predicts that $\mathrm{CCN}$ activation occurs in a grid cell, the portions of the moments and the mass (see Eq. 17) were transferred to the grid-scale cloud droplets. Lin et al. (1983) developed an explicit cloud microphysics model in which interactions between cloud droplets and other hydrometers, such as rain, snow and graupel droplets, are formulated. The autoconversion rate (cloud $\rightarrow$ rain) and the accretion rate of cloud droplets by rain, snow, and graupel (cloud $\rightarrow$ rain, cloud $\rightarrow$ snow, cloud $\rightarrow$ graupel), predicted by WSM6, were used to calculate the transfer of the aerosol moments and mass in the cloud droplets to the other hydrometers.

Particles such as the hydrophobic forms of dust and soot efficiently act as IN in ice and mixed phase clouds. Pagels et al. (2009) found that a mass increase of 2-3 times by the condensation of water and sulfuric acid onto soot agglomerates resulted in a transformation into spherical shapes. We assumed here that the soot loses IN activity after the growth by condensation. Thus, hydrophobic particles in RAQM2 are defined as AGR and COR categories when the hygroscopic mass ( $=$ sum of $\mathrm{SO}_{4}^{2-}, \mathrm{NH}_{4}^{+}, \mathrm{NO}_{3}^{-}, \mathrm{Cl}^{-}$and $\left.\mathrm{SS}\right)$ is less than $50 \%$ of the total dry mass, i.e., the hygroscopic mass is less than the hydrophobic mass (= sum of the UIC, BC, OA and DU).

All components in OA were assumed to be hydrophobic here, although some of the secondary OA was hydrophilic. For the IN activation of aerosols, we used the Lohmann and Diehl (2010) parameterizations for contact freezing and immersion (+ condensation) freezing. We assumed that the IN activation occurred only in a grid cell that contains ice particles predicted by WRF with a temperature lower than $-3^{\circ} \mathrm{C}$. The fractions of frozen droplets for dust and soot particles are assumed to be functions of temperature based on Fig. 1 of Lohmann and Diehl (2010) as follows:

$$
\begin{aligned}
& F_{\text {cn_du }}=-14\left(T_{\mathrm{c}}+3\right) \\
& F_{\text {cn_bc }}=-15\left(T_{\mathrm{c}}+10\right) \\
& F_{\text {im_du }}=-0.1\left(T_{\mathrm{c}}+27\right) \\
& F_{\text {im_bc }}=-0.5\left(T_{\mathrm{c}}+36\right)
\end{aligned}
$$

where $F_{\text {cn_du }}$ and $F_{\text {cn_bc }}$ represent the fractions for the contact freezing of hydrophobic COR and AGR, respectively,
$F_{\text {im_du }}$, and $F_{\text {im_bc }}$ represent the fractions for the immersion freezing of hydrophobic COR and AGR, respectively, and $T_{\mathrm{c}}$ is the grid air temperature $\left({ }^{\circ} \mathrm{C}\right)$. For immersion freezing, the $F_{\text {im_du }}$ and $F_{\text {im_bc }}$ are the exact fractions scavenged into ice particles. For contact freezing, some portion of $F_{\text {cn_du }}$ and $F_{\text {cn_bc }}$ actually coagulated with ice or super-cooled cloud droplets can be scavenged into ice particles. The Brownian coagulation of hydrophobic COR and AGR with cloud ice/water droplets was calculated using the inter-modal coagulation Eqs. (6), (8), (9) and (10). To obtain the size distribution of cloud ice/water droplets, we assumed a simple Khrgian-Mazin-type gamma size distribution (Pruppacher and Klett, 1997):

$n(a)=A a^{2} \exp (-B a)$

where $n(a)$ is the number size distribution function, $A$ and $B$ are parameters related to the moments of the distribution, and $a$ is the particle radius. This Khrgian-Mazin equation is almost identical to the LNSD, with a standard deviation of approximately 1.64 . Thus, assuming a $D_{\mathrm{g}}$ of cloud ice/water droplets of $15 \mu \mathrm{m}$ along with cloud ice/water mixing ratios and their densities, the size distribution can be fixed for the inter-modal Brownian coagulation. Subsequently, aerosols in ice particles are converted to snow via autoconversion (aggregation) and are converted to rain, snow and graupel particles due to accretion with conversion rates predicted by the explicit cloud microphysics parameterization (WSM6).

The below-cloud scavenging process is considered intermodal coagulation with falling hydrometers, such as rain, snow and graupel droplets. Kajino and Kondo (2011) deduced the collision/coalescence equations due to gravitational settling in Eqs. (A37)-(A43) in Sect. A4 of their paper. The LNSD is assumed in their equations, while the size distributions of such hydrometers are often represented by gamma functions. Thus, we first derive the gamma size distributions (GSDs) of the hydrometers as functions of the mixing ratio (Hong and Lin, 2006) and then yield the LNSD converted from the GSD, preserving the three moments.

Once captured in the hydrometeors (rain, snow, and graupel) in any way, a certain portion of the moments and chemical components is assumed to immediately reach the ground in the same manner as Eqs. (1) and (2) of Kajino and Kondo (2011).

\subsubsection{Dry deposition and gravitational sedimentation}

The dry deposition and gravitational sedimentation processes are formulated in the same manner as that given in Appendices 5 and 6 of Kajino and Kondo (2011) through Eqs. (A44) to (A48). With regard to calculating the dry deposition for particles, however, the original parameterization of surface resistance by Zhang et al. (2001) used by Kajino and Kondo (2011) was modified based on comparisons by more recent works (Katata et al., 2008, 2011; Petroff and Zhang, 2010) using observational data to improve the prediction 
accuracy of dry deposition. In the present paper, four important revisions were performed:

1. Based on the assumption that forests have tall canopies and a large leaf surface area that enables a large amount of particles from the atmosphere to be captured, the empirical constant $\varepsilon_{0}$ in Zhang et al. (2001) was set to 5 and 1 for the forest and short vegetation categories, respectively. This modification decreases the surface resistance, resulting in large values of the dry deposition velocity for forests compared with other vegetation.

2. For the collection efficiency by leaves due to inertial impaction, the modified function of Peters and Eiden (1992) (Eq. (7) in Katata et al., 2008) was used. The function was validated with the data for fog deposition $(>1 \mu \mathrm{m})$ onto coniferous and broad-leaved forests in Katata et al. (2008).

3. Collection efficiencies due to interception and Brownian diffusion by Kirsch and Fuchs (1968) and Fuchs (1964) (Eqs. (14) and (16) in Katata et al., 2011), respectively, were also used for vegetative surfaces. Those formulations were verified using the flux data for fine aerosols $(<1 \mu \mathrm{m})$ over the coniferous forest in Katata et al. (2011).

4. For the land use categories of desert, tundra, ice cap, glacier, inland water, and ocean, the surface resistance for non-vegetated surfaces proposed by Petroff and Zhang (2010) were adopted.

After the above modifications, the dry deposition velocity calculated by the modified model better agreed with the observational data than did the original model of Zhang et al. (2001). For example, the size-segregated dry deposition velocity for the vegetative surface decreased and increased by one order of magnitude within the 0.1 - and $1-\mu \mathrm{m}$-diameter range, which is comparable to the performance of the detailed multi-layer particle deposition model by Katata et al. (2011). For ground and water surfaces, a good agreement was found between the modified model calculations and the observations from the literature, as shown in Petroff and Zhang (2010).

\subsubsection{Operator splitting and time splitting for aerosol dynamical modeling}

The operator splitting and time splitting used for the aerosol dynamics module are illustrated in Fig. 2a. In the flow chart, each solid box indicates an operator and the arrows denote the order of operator calculations. $\Delta T_{\text {host }}$ is the longest time step of the host calculation, i.e., horizontal advection and diffusion. In this study, we set $\Delta x=60 \mathrm{~km}$, so $\Delta T_{\text {host }}$ is set to $300 \mathrm{~s}$ after optimizing the CPU time and the numerical diffusion deficit. $\Delta t$ is a split time step within each operator calculation, whereas the $\Delta T$ s denote the integrated time steps of each operator before stepping forward to the next operator. First, the rate of sulfuric acid gas production via homogeneous (gas-phase) chemistry was calculated using SAPRC99 with the Eulerian Backward Iteration method with $\Delta t=150$ $\mathrm{s}$. The production rate of sulfuric acid gas was obtained as $\Delta C_{\mathrm{H}_{2} \mathrm{SO}_{4}} / \Delta T_{\text {host }}$. The nucleation rate $J_{1 \mathrm{~nm}}$ (Kuang et al., 2008) and the condensation rate (Eqs. 15 and 16) were calculated using $C_{\mathrm{H}_{2} \mathrm{SO}_{4}}=\Delta C_{\mathrm{H}_{2} \mathrm{SO}_{4}} / \Delta T_{\text {host }} \times \Delta t(=1 \mathrm{~s})$. Then, the gas-phase concentration $C_{\mathrm{H}_{2} \mathrm{SO}_{4}}$ was distributed into the ATK category to produce new particles and into all categories by condensation simultaneously. After the NPF\&Cond. operator, the intra- and inter-category Brownian coagulation was solved with an arbitrary split time to integrate for $0.5 \Delta T_{\text {host }}$ (150 s). CFL-like conditions were established for Brownian coagulation as

$t_{\mathrm{CFL}}=M_{0}^{i} / \frac{\mathrm{d} M_{0}^{i}}{\mathrm{~d} t}$

where $\Delta t$ is set as the maximum so that it never exceeds $0.5 \times$ $t_{\mathrm{CFL}}$ for all the modes in the categories due to intra- and intercategory coagulations. After the Coag. operator is calculated for $0.5 \Delta T_{\text {host }}$, the condensation of the semi-volatile inorganic and organic components is calculated. The CFL conditions are also introduced for the condensation process as

$t_{\mathrm{CFL}}=1 / k_{\mathrm{W}}$

where $k_{\mathrm{w}}$ is the mass-transfer coefficient $\left(\mathrm{s}^{-1}\right)$ for each mode defined as

$k_{\mathrm{w}}=\frac{\mathrm{d} M}{\mathrm{~d} t} \frac{1}{\left(c_{\infty}-c_{\mathrm{s}}\right)}$

and the time derivative of mass concentration $\mathrm{d} M / \mathrm{d} t$ is obtained from Eqs. (15) and (16). $\Delta t$ is set as the maximum so that it never exceeds $0.1 \times t_{\mathrm{CFL}}$ for all modes of the categories. The condensation process was integrated for the host time step period (300 s) with an arbitrary time step. After the volatile components condensation operator was calculated, the Coag. operator was calculated again for the remaining half of the host time step (150 s). Other processes then followed, including sedimentation, dry deposition, subgridscale wet deposition, grid-scale CCN activation and cloud microphysics.

Strictly speaking, NPF, the condensation of sulfuric acid gas and other semi-volatile components, and Brownian coagulation should be solved with the smallest time step, i.e., $1 \mathrm{~s}$, to calculate the aerosol particle growth consistently. However, although ISORROPIA2 is computationally efficient compared with other models (Fountoukis and Nenes, 2007), solving the thermodynamic equilibrium state among multi-component species for every $1 \mathrm{~s}$ for all modes of the categories in the regional scale simulation is still far from feasible for our computational resources. To avoid operator split problems in the current implementation of the model, the $\Delta T$ of the Brownian coagulation is divided into two and 
inserted separately between the two condensational operators.

\subsubsection{Time evolution of the moments and the LNSD parameters in each process operator}

At any step during the time integration, each mode of the categories has specific size parameters $\left(N, D_{\mathrm{g}}, \sigma_{\mathrm{g}}\right)$ to characterize its LNSD. Then, the $M_{0}$ and $M_{2}$ derived by Eq. (2) along with the chemical components (listed in Table 2) are transported via advection, turbulent diffusion, and sub-grid scale convection. Then, there are three moments after the transport operator, $M_{0}, M_{2}$ and $M_{3}$, which are diagnosed by the total mass and predetermined density of each chemical component. Using the three moments, the size parameters $\left(N, D_{\mathrm{g}}\right.$, $\sigma_{\mathrm{g}}$ ) after the transport operators are obtained by Eq. (2). This is the case for the transport operators but also for the aerosol process operators (Fig. 2a), as illustrated in Fig. 2b. To obtain $\mathrm{d} M_{0} / \mathrm{d} t, \mathrm{~d} M_{2} / \mathrm{d} t$, and $\mathrm{d} M_{3} / \mathrm{d} t$ for the condensation operator in Eq. (15), any moments necessary in the equation are derived by the size parameters. Using Eq. (15), $M_{0}, M_{2}$ and $M_{3}$ after the condensation operator are obtained, and subsequently $N$, $D_{\mathrm{g}}$ and $\sigma_{\mathrm{g}}$ after the operator. The same procedure is applied for other process operators such as sedimentation, dry deposition, subgrid-scale wet deposition, grid-scale CCN activation and cloud microphysics but not for the coagulation operator, where $\mathrm{d} M_{6} / \mathrm{d} t$ needs to be calculated instead of $\mathrm{d} M_{2} / \mathrm{d} t$ (Eqs. 3-10). For the coagulation operator, any moments necessary for the coagulation equations (Eqs. 3-10) are derived by the size parameters $N, D_{\mathrm{g}}$ and $\sigma_{\mathrm{g}}$ before the coagulation operator, $M_{0}, M_{3}$ and $M_{6}$ after the coagulation operator is obtained by the equations, and then $N, D_{\mathrm{g}}$ and $\sigma_{\mathrm{g}}$ after the coagulation operator are derived. We set a minimum $\sigma_{g}$ value of 1.0 and the maximum values at 1.7 for ATK, ACM and AGR and 2.0 for COR to avoid unrealistic values. When $\sigma_{\mathrm{g}}$ exceeds any of these limits, $\sigma_{\mathrm{g}}$ is adjusted to the limit values preserving $M_{0}$ and $M_{3}$ (thus, $M_{2}$ is changed accordingly).

\section{Observation}

\subsection{EANET monitoring network data}

Acid Deposition Monitoring Network in East Asia (EANET) data were used to evaluate the model. The guidelines, technical documents, monitoring reports and quality assurance and quality control programs are available at http://www.eanet. cc/product.html. We used hourly $\mathrm{SO}_{2}, \mathrm{NO}_{\mathrm{x}}, \mathrm{O}_{3}, \mathrm{PM}_{2.5}$ and $\mathrm{PM}_{10}$ concentrations and meteorological parameters, and 1or 2- week concentrations of gases $\left(\mathrm{SO}_{2}, \mathrm{NH}_{3}, \mathrm{HNO}_{3}\right.$, and $\mathrm{HCl})$ and aerosol components $\left(\mathrm{SO}_{4}^{2-}, \mathrm{NO}_{3}^{-}, \mathrm{Cl}^{-}, \mathrm{NH}_{4}^{+}, \mathrm{Na}^{+}\right.$, $\mathrm{Mg}^{2+}, \mathrm{K}^{+}$, and $\mathrm{Ca}^{2+}$ ) using the filter pack method (FP). The long-duration sampling of FP causes several artifact problems; volatilization of $\mathrm{NH}_{4} \mathrm{NO}_{3}$ and $\mathrm{NH}_{4} \mathrm{Cl}$ collected on a filter occur during sampling and/or high humidity may reduce the measured gas concentration due to trapping by con- densed water in the filter pack. To avoid these problems, only total nitrate (T-NO$-\mathrm{NO}_{3}^{-} ; \mathrm{HNO}_{3}^{-}$gas plus $\mathrm{NO}_{3}^{-}$aerosol), total ammonium $\left(\mathrm{T}-\mathrm{NH}_{4}^{+} ; \mathrm{NH}_{3}\right.$ gas plus $\mathrm{NH}_{4}^{+}$aerosol), and total chloride $\left(\mathrm{T}_{-} \mathrm{Cl}^{-} ; \mathrm{HCl}\right.$ gas plus $\mathrm{Cl}^{-}$aerosol) are used in this study.

To obtain the anthropogenic $\mathrm{SO}_{4}^{2-}$ and $\mathrm{Ca}^{2+}$ originating from the Asian dust (calcite), nss- $\mathrm{SO}_{4}^{2-}$ and nss- $\mathrm{Ca}^{2+}$ were defined excluding the contribution of sea salt using a standard mean chemical composition of sea water (DOE, 1994) as follows:

$\left[\mathrm{nss}-\mathrm{SO}_{4}^{2-}\right]=\left[\mathrm{SO}_{4}^{2-}\right]-0.251 \times\left[\mathrm{Na}^{+}\right]$

$\left[\right.$ nss- $\left.\mathrm{Ca}^{2+}\right]=\left[\mathrm{Ca}^{2+}\right]-0.038 \times\left[\mathrm{Na}^{+}\right]$

where [ ] denotes the weight concentrations in $\mu \mathrm{g} \mathrm{m}^{-3}$.

Among the EANET stations, six stations in Japan are selected for the model evaluation, as depicted in Fig. 1 and listed in Table 4. The red triangles denote the stations located on small islands or isolated capes in down-wind regions. These stations were situated in areas without nearby large anthropogenic emission sources and without the complexity of local orographic winds; therefore, high concentration episodes mostly coincided with synoptic-scale disturbances and were well simulated by regional-scale models. Conversely, because those stations were very close to ocean surfaces, the regional-scale simulations of ocean-originated species such as sea salt did not often agree well with the observations. We often obtained a better agreement for the sea salt-originated components at inland or mountainous stations.

\subsection{Q-AMS aerosol observation data at the CHAAMS site}

Because the temporal resolution of the EANET ionic aerosol component measurements is 2 weeks, the simulated transport and transformation of aerosol components cannot be evaluated. Alternatively, we used the hourly concentrations of $\mathrm{PM}_{1}-\mathrm{nss}-\mathrm{SO}_{4}^{2-}, \mathrm{PM}_{1}-\mathrm{NO}_{3}^{-}, \mathrm{PM}_{1}-\mathrm{Cl}^{-}$, and $\mathrm{PM}_{1}-\mathrm{NH}_{4}^{+}$ (50\% cutoff of aerosols with an aerodynamic diameter of $1 \mu \mathrm{m}$ ), measured using a quadrupole aerosol mass spectrometer (Aerodyne Research Inc., Q-AMS) at the Cape Hedo Atmospheric and Aerosol Monitoring Station (CHAAMS) site (Takami et al., 2007; Takiguchi et al., 2008). The CHAAMS site is located within the same premises as the EANET Hedo station.

\section{Results and discussion}

\subsection{Bulk mass concentrations of gaseous species}

It is necessary to predict the $\mathrm{O}_{3}$ concentration precisely because it is an important oxidizing agent in the atmosphere 
Table 4. Description of the EANET remote sites and the CHAAMS site used in this study. Each station is depicted in Fig. 1.

\begin{tabular}{llllllllllll}
\hline & $\begin{array}{l}\text { Longitude } \\
(\mathrm{E})\end{array}$ & $\begin{array}{l}\text { Latitude } \\
(\mathrm{N})\end{array}$ & $\begin{array}{l}\text { Altitude } \\
(\mathrm{m} \text { a.s.1.) }\end{array}$ & Character-istics & $\mathrm{X}$ & $\mathrm{Y}$ & $\mathrm{MT}$ & AT & AT-PM 2.5 & FP & AMS \\
\hline 1. Rishiri & $141^{\circ} 12^{\prime}$ & $45^{\circ} 07^{\prime}$ & 40 & Remote & 68 & 48 & $1 \mathrm{~h}$ & $1 \mathrm{~h}$ & $1 \mathrm{~h}$ & \\
2. Tappi & $140^{\circ} 21^{\prime}$ & $41^{\circ} 15^{\prime}$ & 105 & Remote & 69 & 41 & $1 \mathrm{~h}$ & $1 \mathrm{~h}$ & N.A. & N.A. \\
3. Ogasawara & $142^{\circ} 13^{\prime}$ & $27^{\circ} 05^{\prime}$ & 230 & Remote & 77 & 16 & $1 \mathrm{~h}$ & $1 \mathrm{~h}$ & N.A. & $1 \mathrm{w}$. N.A. \\
4. Sado & $138^{\circ} 24^{\prime}$ & $38^{\circ} 14^{\prime}$ & 136 & Remote & 67 & 35 & $1 \mathrm{~h}$ & $1 \mathrm{~h}$ & N.A. & $2 \mathrm{w}$ & N.A. \\
5. Oki & $133^{\circ} 11^{\prime}$ & $36^{\circ} 17^{\prime}$ & 90 & Remote & 60 & 30 & $1 \mathrm{~h}$ & $1 \mathrm{~h}$ & $1 \mathrm{~h}$ & $2 \mathrm{w}$ & N.A. \\
6. Hedo \& CHAAMS & $128^{\circ} 15^{\prime}$ & $26^{\circ} 52^{\prime}$ & 60 & Remote & 54 & 12 & $1 \mathrm{~h}$ & $1 \mathrm{~h}$ & N.A. & $2 \mathrm{w}$ & $1 \mathrm{~h}$ \\
\hline
\end{tabular}

X,Y: Model grid number; MT: meteorological parameters, AT: automatically monitored $\left(\mathrm{NO}_{\mathrm{X}}, \mathrm{O}_{3}, \mathrm{SO}_{2}, \mathrm{PM}_{10}\right.$; PM 2.5 is only available at Rishiri and Oki), FP: filter pack method (Aerosol inorganic components), AMS: aerosol mass spectrometer, only available at CHAAMS. CHAAMS is located within the same premises as the EANET Hedo station. 1 h: hourly, 1 w: weekly, 2 w: 2 weekly.

for secondary aerosol formation. This prediction is also important because $\mathrm{O}_{3}$ is a source of the most efficient oxidants in the troposphere, $\mathrm{OH}$ radicals. Because $\mathrm{O}_{3}$ is a relatively longer-lived species, the contribution of inter-continental transport and stratospheric ozone intrusion is substantial (Sudo and Akimoto, 2007; Nagashima et al., 2010). Consequently, the seasonal trends can never be reproduced by a tropospheric regional-scale model itself without appropriate seasonal variations of the lateral and upper (tropopause) boundary conditions. Therefore, we used the climatological simulation results of monthly $\mathrm{NO}_{\mathrm{x}}, \mathrm{O}_{\mathrm{x}}, \mathrm{CO}$ and VOCs concentrations using a global-scale stratospheric and tropospheric chemistry-climate model (MRI-CCM2; Deushi and Shibata, 2011) as the boundary conditions for RAQM2.

Table 5 summarizes the comparative statistical analysis between the observations and simulations for all the available data at the six EANET stations. The simulation of the daily maximum 8-h mean $\mathrm{O}_{3}$ was found to be successful, as the medians of the observations and simulations were similar and the Root Mean Square Errors (RMSEs) were much lower than the medians. The correlation coefficient $R$ is 0.47 and $96 \%$ of the simulation values are within a factor of 2 of the observed values. The $R$ of the daily mean $\mathrm{SO}_{2}$ and $\mathrm{NO}_{\mathrm{x}}$ concentrations were the same as that of $\mathrm{O}_{3}$, but there were larger discrepancies in the medians, RMSEs, FAC2 and FAC5. Because these EANET stations are located over remote ocean areas, the $\mathrm{O}_{3}$ temporal variations were always incremented by background concentrations due to the longrange transport. While this smaller variation/background ratio of $\mathrm{O}_{3}$ resulted in better scores for the RMSEs, FAC2 and FAC5 than for $\mathrm{SO}_{2}$ and $\mathrm{NO}_{\mathrm{x}}$, the similar levels of $\mathrm{R}$ indicated that the transport pattern predictabilities of the three species were similar. The simulated $\mathrm{O}_{3}$ was not biased toward the observation, but the simulated $\mathrm{SO}_{2}$ and $\mathrm{NO}_{\mathrm{x}}$ were biased by $30-50 \%$.

\subsection{Bulk mass concentrations of aerosol chemical components}

Figure 3 presents a scatter plot between the observed and modeled concentrations of biweekly chemical components at the Rishiri, Oki and Hedo stations. These stations are located over a wide range, from the northeast to the southwest of the Japan archipelago, so different types of long-range transport patterns from the Asian continent can be evaluated. We also selected these stations because the $\mathrm{PM}_{2.5}$ mass concentrations were only monitored along with $\mathrm{PM}_{10}$ at Rishiri and Oki and because the AMS $\mathrm{PM}_{1}$ measurements were taken only at Hedo.

The statistics of the corresponding data at all six stations are listed in Table 5. The medians of the modeled nss- $\mathrm{SO}_{4}^{2-}$ and $\mathrm{T}_{-} \mathrm{NH}_{4}^{+}$were approximately $30 \%$ smaller than the observed values, whereas the modeled $\mathrm{T}^{-\mathrm{NO}_{3}^{-}}$was almost double that observed. The nitric acid and ammonia are semivolatile in atmospheric conditions and were partitioned into gas and aerosol phases. However, due to the artifact problems mentioned in Sect. 3.1, the gas-aerosol partitioning was not evaluated. The partitioning is essentially important for the transport of the species because the dry and wet deposition efficiencies of nitric acid and ammonia in gas and aerosol phases are very different (Kajino et al., 2008). The modeled gas-aerosol partitioning of the semi-volatile components should be evaluated using accurate measurements for $\mathrm{HNO}_{3}$ and $\mathrm{NH}_{3}$ gases in the future to identify the possible causes of the discrepancies between the model and observation. The RMSEs of nss- $\mathrm{SO}_{4}^{2-}, \mathrm{NH}_{4}^{+}$, and $\mathrm{NO}_{3}^{-}$were comparable to the medians, and the $R^{2}$ values were always greater than 0.5 .

$\mathrm{T}_{-} \mathrm{Cl}^{-}$and $\mathrm{Na}^{+}$mainly originate from sea salt particles because the EANET stations are near the ocean. Natural aerosols are usually difficult to simulate due to the large uncertainties in the emission flux estimates, and the corresponding R-values were lower than for the other chemical components. Still, the RMSEs and modeled medians were close to the observed medians. Nss- $\mathrm{Ca}^{2+}$ was considered to originate from Asian dust particles, which contain calcite; these are also natural aerosols and were difficult to simulate. The modeled median was approximately double that measured. We assumed uniform compositions for the dust emission from the whole model domain, which may not have been realistic. Still, a large value of $R$ was obtained for nss- $\mathrm{Ca}^{2+}$ because the long-range transport of Asian dust in Japan is the most 

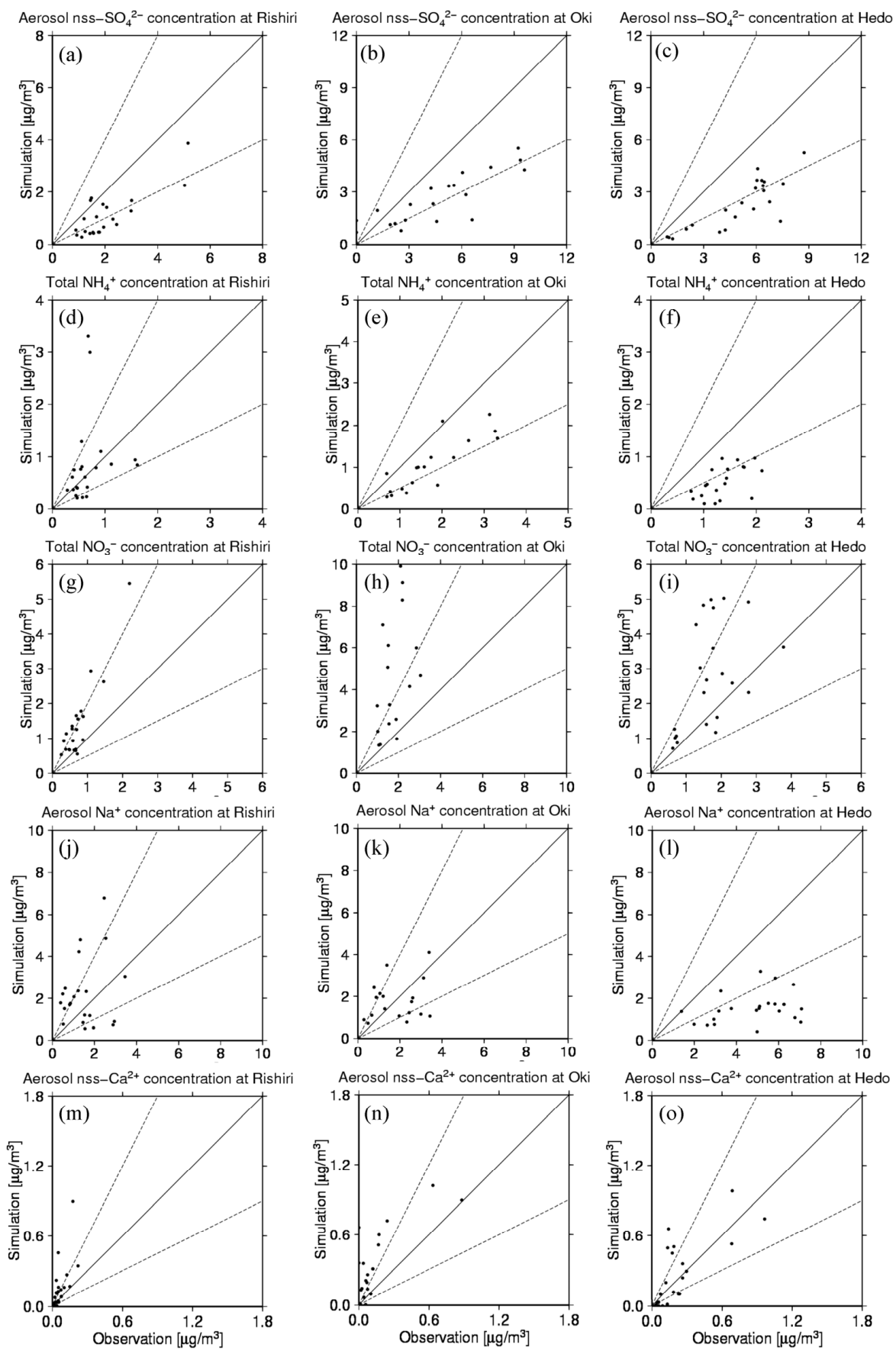

Fig. 3. Scatter plots between the observed and modeled biweekly concentrations $(\mathbf{a}-\mathbf{c}) \mathrm{nss}-\mathrm{SO}_{4}^{2-}$, (d-f) $\mathrm{T}-\mathrm{NH}_{4}^{+},(\mathbf{g}-\mathbf{i}) \mathrm{T}^{-\mathrm{NO}_{3}^{-}}$, (j-l) $\mathrm{Na}^{+}$, and (m-o) nss- $\mathrm{Ca}^{2+}$ at (left) Rishiri, (center) Oki and (right) Hedo. Solid lines denote the 1:1 line, and dashed lines denote the factor of 2 envelope.

influential in spring, and this feature was well reproduced by RAQM2. The $R$ s at the western stations, where the dust transport is more frequent, were larger, with 0.74 and 0.76 at Hedo and Oki, respectively.

\subsection{Size distributions of total aerosol mass}

Figure 4 presents the daily mean observed and modeled concentrations of $\mathrm{PM}_{10}$ and $\mathrm{PM}_{2.5}$, the $\mathrm{PM}_{2.5} / \mathrm{PM}_{10}$ concentration ratio and modeled constituent fractions of $\mathrm{PM}_{10}, \mathrm{PM}_{2.5}$, and $\mathrm{PM}_{1}$ at the Rishiri and Oki stations. $\mathrm{PM}_{2.5}$ includes 
Table 5. Statistical analysis for comparing all EANET observation and simulation data for 2006.

\begin{tabular}{|c|c|c|c|c|c|c|c|c|}
\hline & Unit & $\begin{array}{l}\text { Number } \\
\text { of data }\end{array}$ & $\begin{array}{r}\text { Median } \\
\text { (Obs.) }\end{array}$ & $\begin{array}{r}\text { Median } \\
\text { (Sim.) }\end{array}$ & RMSE & $R$ & $\mathrm{FAC}^{\mathrm{a}}$ & $\mathrm{FAC}^{\mathrm{b}}$ \\
\hline \multicolumn{9}{|c|}{ Daily mean bulk gas concentrations $\left(\mathrm{AT}^{\mathrm{d}}\right.$ ) } \\
\hline $\mathrm{O}_{3}^{\mathrm{c}}$ & ppbv & 2093 & 50.3 & 51.2 & 16.9 & 0.47 & 0.96 & 1.00 \\
\hline $\mathrm{SO}_{2}$ & ppbv & 2052 & 0.17 & 0.25 & 0.70 & 0.52 & 0.36 & 0.64 \\
\hline $\mathrm{NO}_{\mathrm{x}}$ & ppbv & 1819 & 0.80 & 0.58 & 1.1 & 0.49 & 0.52 & 0.86 \\
\hline \multicolumn{9}{|c|}{ 1- or 2-weekly bulk concentrations of chemical compounds $\left(\mathrm{FP}^{\mathrm{e}}\right)$} \\
\hline $\mathrm{Nss}^{\mathrm{S}} \mathrm{SO}_{4}^{2-}$ & $\mu \mathrm{g} \mathrm{m}^{-3}$ & 152 & 1.9 & 1.3 & 1.9 & 0.70 & 0.46 & 0.80 \\
\hline $\mathrm{T}-\mathrm{NH}_{4}^{+}$ & $\mu g \mathrm{~m}^{-3}$ & 138 & 0.71 & 0.45 & 0.69 & 0.52 & 0.50 & 0.81 \\
\hline $\mathrm{T}-\mathrm{NO}_{3}^{-}$ & $\mu \mathrm{g} \mathrm{m}^{-3}$ & 144 & 0.92 & 1.8 & 2.2 & 0.59 & 0.47 & 0.87 \\
\hline $\mathrm{T}-\mathrm{Cl}^{-}$ & $\mu \mathrm{g} \mathrm{m}^{-3}$ & 144 & 3.7 & 2.8 & 4.2 & 0.13 & 0.42 & 0.89 \\
\hline $\mathrm{Na}^{+}$ & $\mu \mathrm{g} \mathrm{m}^{-3}$ & 144 & 2.3 & 1.4 & 2.5 & 0.13 & 0.38 & 0.85 \\
\hline $\mathrm{Nss}-\mathrm{Ca}^{2+}$ & $\mu \mathrm{g} \mathrm{m}{ }^{-3}$ & 152 & 0.056 & 0.11 & 0.24 & 0.55 & 0.38 & 0.67 \\
\hline \multicolumn{9}{|c|}{ Daily mean $\mathrm{PM}_{2.5}$ and $\mathrm{PM}_{10}$ concentration and their ratios (AT) } \\
\hline $\mathrm{PM}_{2.5}$ & $\mu \mathrm{g} \mathrm{m}{ }^{-3}$ & 696 & 8.8 & 5.2 & 10.8 & 0.45 & 0.52 & 0.87 \\
\hline $\mathrm{PM}_{10}$ & $\mu \mathrm{g} \mathrm{m} \mathrm{m}^{-3}$ & 2141 & 17.7 & 8.3 & 19.1 & 0.65 & 0.45 & 0.81 \\
\hline $\mathrm{PM}_{2.5} / \mathrm{PM}_{10}$ & - & 674 & 0.57 & 0.49 & 0.26 & 0.018 & 0.83 & 1.00 \\
\hline
\end{tabular}

sub-micron aerosols and a portion of super-micron aerosols, such as sea salt and dust particles, so the $\mathrm{PM}_{2.5} / \mathrm{PM}_{10}$ ratio provided some indication of the mass size distribution of the super-micron particles or mass ratios of the anthropogenic (mostly sub-micron) and natural origin aerosols (mostly super-micron) (Kajino and Kondo, 2011). Notably, the modeled $\mathrm{PM}_{2.5}$ and $\mathrm{PM}_{10}$ were derived using Eq. (17) by cutting each wet aerosol particle in a category at the exact diameter $(2.5$ and $10 \mu \mathrm{m}$, respectively), so the size classification property differed from that of the instruments; the classification is characterized by the so-called cut-off curve. As shown in Table 5, the medians of the modeled $\mathrm{PM}_{2.5}$ and $\mathrm{PM}_{10}$ are $40 \%$ and $50 \%$ smaller, respectively, than the observations. The RMSEs were comparable to the median values, and approximately half and $80 \%$ of the simulated values are within factors of 2 and 5 of the observed values, respectively. Note here that the statistics for $\mathrm{PM}_{10}$ included data from all six stations, whereas those for $\mathrm{PM}_{2.5}$ included only those from Oki and Rishiri. The modeled and observed median of the $\mathrm{PM}_{2.5} / \mathrm{PM}_{10}$ ratio agreed well, as the RMSE is small and more than $80 \%$ of the simulated values are within a factor of 2 of the observed values, except that $R$ is almost zero. Together with the comparisons shown in Fig. 4e and $\mathrm{f}$, the daily variations of the $\mathrm{PM}_{2.5} / \mathrm{PM}_{10}$ ratio may have failed to be simulated, but longer-term features were well reproduced by the model. The variations of the measured ratios were not large, with the median ranging from 0.4 to 0.6 . The values at $\mathrm{Oki}$ (0.9) in August were excluded because the measured $\mathrm{PM}_{2.5}$ data were missing during most of the period. The modeled mean $\mathrm{PM}_{2.5} / \mathrm{PM}_{10}$ ratios were also within the same range of 0.4-0.6, except at Rishiri from January to March. The overestimation of the model during the period indicates that the modeled size was smaller than that observed.

The 10-d mean fractions of the $\mathrm{PM}_{10}, \mathrm{PM}_{2.5}$, and $\mathrm{PM}_{1}$ constituents are also shown in Fig. 4g-1. The red, green, yellow, blue, and sky blue columns indicate the total dry mass of ATK and ACM, the total dry mass of AGR, the dust mass (DU) of COR, the sea salt mass $\left(\mathrm{SS}+\mathrm{Cl}^{-}\right)$of $\mathrm{COR}$, and the other dry mass of COR, respectively. The ATK, ACM, and AGR are mainly of anthropogenic origin and are composed of submicron particles $\left(\mathrm{PM}_{1}\right)$. COR is mainly of natural origin and was partitioned into $\mathrm{PM}_{2.5}$ and $\mathrm{PM}_{10}$. The ATK, ACM, and AGR particles accounted for more than $90 \%$ of the $\mathrm{PM}_{1}$ except in spring and autumn at Rishiri and spring at Oki. The COR particles accounted for more than $90 \%$ of the $\mathrm{PM}_{10}$ except in summer. The modeled fractions of ATK, ACM, and AGR in $\mathrm{PM}_{2.5}$ and $\mathrm{PM}_{10}$ became larger in summer because the sea salt production and dust transport are less pronounced than during the cold seasons. The $\mathrm{PM}_{2.5} / \mathrm{PM}_{10}$ ratio of the chemical components was an excellent indicator of the mixing type of inorganic components (Kajino and Kondo, 2011), but the ratio of the total aerosol mass was merely an indicator of the COR category sizes. The modeled fractions of the $\mathrm{PM}_{2.5}$ and $\mathrm{PM}_{10}$ constituents did not differ greatly from one another, but those of $\mathrm{PM}_{1}$ and $\mathrm{PM}_{10}$ were very different. Unfortunately, we did not obtain $\mathrm{PM}_{1}$ mass concentration data, but a comparison between the modeled and observed $\mathrm{PM}_{1} / \mathrm{PM}_{10}$ ratio, if available, may 

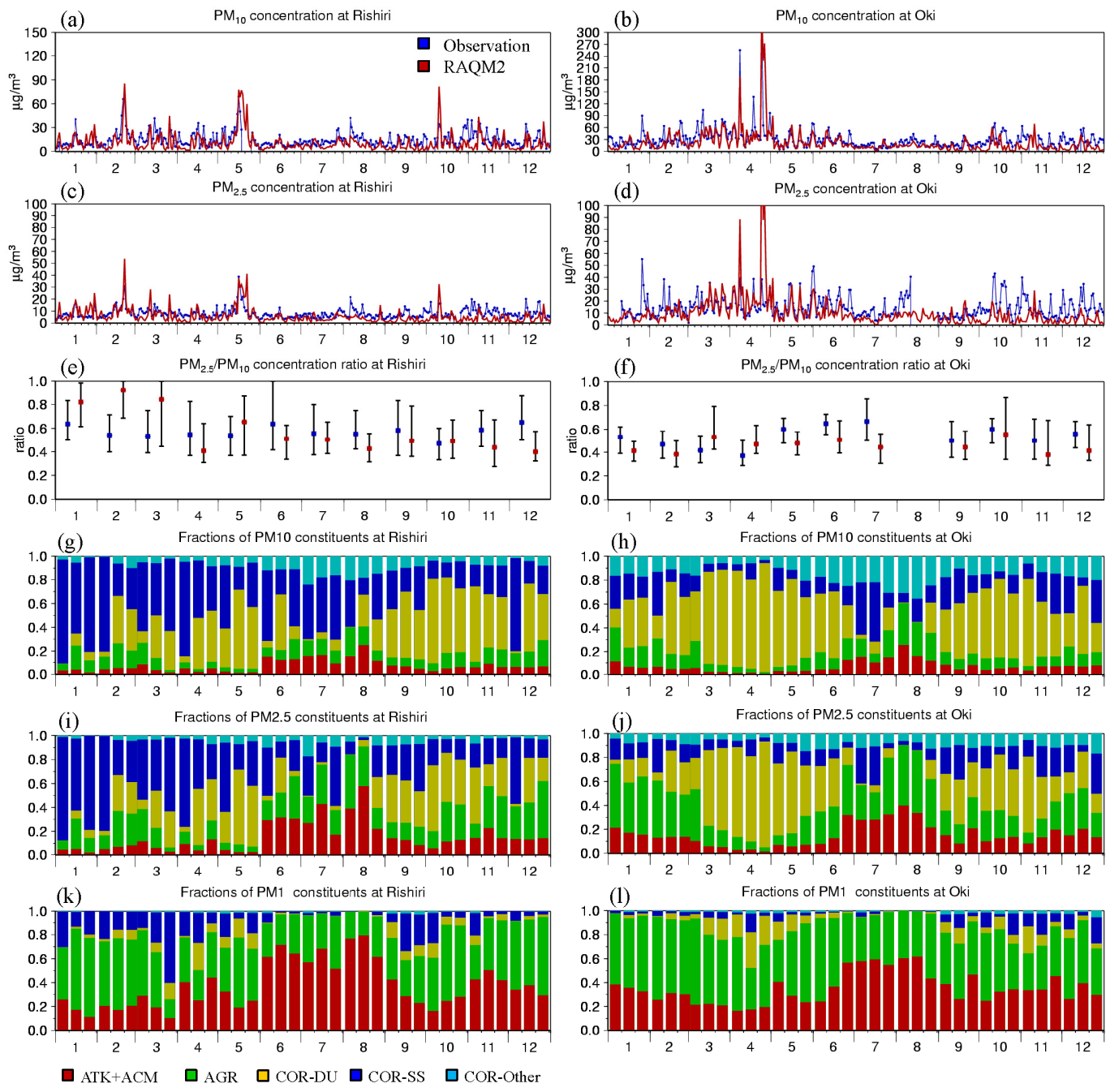

Fig. 4. Daily mean observed (blue) and modeled (red) concentrations of (a-b) $\mathrm{PM}_{10}$, (c-d) $\mathrm{PM}_{2.5}$, (e-f) $\mathrm{PM}_{2.5} / \mathrm{PM}_{10}$ concentration ratios (the median with 75 and 25 percentile values) and modeled constituent fractions of $(\mathbf{g}-\mathbf{h}) \mathrm{PM}_{10}$, (i-j) $\mathrm{PM}_{2.5}$, and $(\mathbf{k}-\mathbf{l}) \mathrm{PM}_{1}$ concentrations at (left) Rishiri and (right) Oki. Among the constituents, $\mathrm{ATK}+\mathrm{ACM}$ (red) is the total dry mass $\left(\mathrm{SO}_{4}^{2-}, \mathrm{NH}_{4}^{+}, \mathrm{NO}_{3}^{-}, \mathrm{Cl}^{-}\right.$, UID and OA) of the ATK and ACM categories, AGR (green) is the total dry mass (UID, $\mathrm{BC}, \mathrm{OA}, \mathrm{SO}_{4}^{2-}, \mathrm{NH}_{4}^{+}, \mathrm{NO}_{3}^{-}$, and $\mathrm{Cl}^{-}$) of the AGR category, COR-DU (yellow) is the dust mass (DU) of the COR category, COR-SS (blue) is the sea-salt mass $\left(\mathrm{SS}+\mathrm{Cl}^{-}\right.$) in the COR category and COR-Other (sky blue) includes the other components (UID, $\mathrm{BC}, \mathrm{OA}, \mathrm{SO}_{4}^{2-}, \mathrm{NH}_{4}^{+}$, and $\mathrm{NO}_{3}^{-}$) in the $\mathrm{COR}$ category.

provide additional important implications for modeling studies.

\subsection{Size distributions and mixing types of inorganic components}

\subsubsection{Relationship between chemical size distribution and mixing types}

Figure 5 shows the observed and modeled (left) daily mean $\mathrm{PM}_{1}$ concentrations of nss- $\mathrm{SO}_{4}^{2-}, \mathrm{NH}_{4}^{+}, \mathrm{NO}_{3}^{-}$, and $\mathrm{Cl}^{-}$and (right) the biweekly mean bulk concentrations of nss- $\mathrm{SO}_{4}^{2-}$, $\mathrm{T}-\mathrm{NH}_{4}^{+}, \mathrm{T}-\mathrm{NO}_{3}^{-}, \mathrm{T}_{-} \mathrm{Cl}^{-}, \mathrm{Na}^{+}$, and nss- $\mathrm{Ca}^{2+}$. To derive the modeled $\mathrm{PM}_{1}$ concentrations for comparison with the AMS data, Eq. (17) was again applied. Notably, the equation was applied for the modeled "dry" size distribution, whereas it was applied for the "wet" size distribution for the cases of $\mathrm{PM}_{2.5}$ and $\mathrm{PM}_{10}$, corresponding to the measurement techniques.

Table 6 summarizes the statistical analysis of the corresponding data shown in Fig. 5. In summer, the Pacific high is influential, carrying a clean maritime air mass to Hedo. In cold seasons, long-range transport is predominant from the Asian continent via cyclonic fronts or anticyclones propagating eastward. Therefore, the air pollutant concentrations are low in summer and high in spring, autumn, and winter. 
Table 6. Statistical analysis for comparing between observation and simulation at the Hedo EANET and CHAAMS stations.

\begin{tabular}{|c|c|c|c|c|c|c|c|c|}
\hline & unit & $\begin{array}{l}\text { Number } \\
\text { of data }\end{array}$ & $\begin{array}{r}\text { Median } \\
\text { (Obs.) }\end{array}$ & $\begin{array}{r}\text { Median } \\
\text { (Sim.) }\end{array}$ & RMSE & $R$ & FAC2 & FAC5 \\
\hline \multicolumn{9}{|c|}{ Daily $\mathrm{PM}_{1}$ concentrations $\left(\mathrm{AMS}^{\mathrm{a}}\right)$} \\
\hline $\mathrm{PM}_{1}$-nss-SO $\mathrm{SO}_{4}^{2-}$ & $\mu g \mathrm{~m}^{-3}$ & 199 & 4.2 & 1.3 & 4.4 & 0.57 & 0.28 & 0.72 \\
\hline $\mathrm{PM}_{1}-\mathrm{NH}_{4}^{+}$ & $\mu \mathrm{g} \mathrm{m}^{-3}$ & 199 & 1.0 & 0.34 & 1.0 & 0.56 & 0.28 & 0.70 \\
\hline $\mathrm{PM}_{1}-\mathrm{NO}_{3}^{-}$ & $\mu g \mathrm{~m}^{-3}$ & 199 & 0.088 & 0.080 & 0.15 & 0.30 & 0.53 & 0.90 \\
\hline $\mathrm{PM}_{1}-\mathrm{Cl}^{-}$ & $\mu \mathrm{g} \mathrm{m}^{-3}$ & 197 & 0.027 & 0.016 & 0.088 & 0.097 & 0.26 & 0.58 \\
\hline \multicolumn{9}{|c|}{ 2-weekly bulk concentrations of chemical compounds $\left(\mathrm{FP}^{\mathrm{b}}\right)$} \\
\hline $\mathrm{Nss}-\mathrm{SO}_{4}^{2-}$ & $\mu \mathrm{g} \mathrm{m}^{-3}$ & 22 & 5.9 & 2.0 & 3.0 & 0.83 & 0.32 & 0.86 \\
\hline $\mathrm{T}-\mathrm{NH}_{4}^{+}{ }^{+}$ & $\mu \mathrm{g} \mathrm{m}^{-3}$ & 20 & 1.4 & 0.47 & 0.91 & 0.56 & 0.20 & 0.80 \\
\hline $\mathrm{T}-\mathrm{NO}_{3}^{-}$ & $\mu \mathrm{g} \mathrm{m}^{-3}$ & 22 & 1.7 & 2.6 & 1.7 & 0.49 & 0.72 & 1 \\
\hline $\mathrm{T}-\mathrm{Cl}^{-}$ & $\mu \mathrm{g} \mathrm{m}^{-3}$ & 22 & 8.2 & 2.8 & 5.6 & 0.35 & 0.22 & 0.86 \\
\hline $\mathrm{Na}^{+}$ & $\mu \mathrm{g} \mathrm{m}^{-3}$ & 22 & 5.1 & 1.6 & 3.6 & 0.30 & 0.22 & 0.86 \\
\hline Nss-Ca ${ }^{2+}$ & $\mu \mathrm{g} \mathrm{m}^{-3}$ & 22 & 0.14 & 0.11 & 0.19 & 0.74 & 0.55 & 0.81 \\
\hline \multicolumn{9}{|c|}{ 2-weekly $\mathrm{PM}_{1}$ to total concentration ratios (AMS/FP) } \\
\hline $\mathrm{Nss-} \mathrm{SO}_{4}^{2-}$ & - & 12 & 0.85 & 0.66 & 0.32 & - & 0.92 & 1 \\
\hline $\mathrm{T}-\mathrm{NH}_{4}^{+}{ }^{+}$ & - & 12 & 0.81 & 0.71 & 0.26 & - & 0.92 & 1 \\
\hline $\mathrm{T}-\mathrm{NO}_{3}^{-}$ & - & 12 & 0.054 & 0.035 & 0.027 & - & 0.75 & 1 \\
\hline $\mathrm{T}-\mathrm{Cl}^{-}$ & - & 12 & 0.0038 & 0.0080 & 0.0082 & - & 0.33 & 0.67 \\
\hline
\end{tabular}

a Measured by quadrupole aerosol mass spectrometer (Aerodyne Research Inc., Q-AMS). ${ }^{\mathrm{b}}$ Measured by the filter pack method.

These seasonal features and daily variations were successfully reproduced by the model. The model results of the natural aerosols, such as sea salt $\left(\mathrm{Na}^{+}\right)$and Asian dust $\left(\mathrm{Ca}^{2+}\right)$, at Hedo were also successful. The Asian dust transport events in spring and autumn were found in both the observations and simulations.

Although the variations were well simulated, the levels were underestimated for some components, such as $\mathrm{PM}_{1}$ nss- $\mathrm{SO}_{4}^{2-}$ and $\mathrm{PM}_{1}-\mathrm{NH}_{4}^{+}$. The modeled medians were approximately $30 \%$ of those observed (Table 6). The model also underestimated the bulk nss- $\mathrm{SO}_{4}^{2-}$ and $\mathrm{T}-\mathrm{NH}_{4}^{+}$, and the underestimation was consistent with that for $\mathrm{PM}_{1}$. The underestimations of $\mathrm{PM}_{1}$-nss- $\mathrm{SO}_{4}^{2-}$ and $\mathrm{PM}_{1}-\mathrm{NH}_{4}^{+}$were most likely due to underestimating the bulk mass. The trends and values of $\mathrm{PM}_{1}-\mathrm{NO}_{3}^{-}$were well predicted by the model, whereas the $\mathrm{T}_{-} \mathrm{NO}_{3}^{-}$was overestimated.

Figure 6 presents the (left) biweekly mean $\mathrm{PM}_{1}$ to the total (gas plus aerosol) concentration ratios for nss- $\mathrm{SO}_{4}^{2-}, \mathrm{T}-\mathrm{NH}_{4}^{+}$, $\mathrm{T}-\mathrm{NO}_{3}^{-}$, and $\mathrm{T}-\mathrm{Cl}^{-}$. The observed values were depicted only when the available hourly AMS data exceeded 50\% during each biweekly FP period (more than $140 \mathrm{~h}$ of data over 2 weeks). The statistical values between the observed and modeled data are listed in Table 6. Figure 6 also presents (right) the biweekly mean fractions of gas and aerosol categories for each inorganic component. The observed median of the $\mathrm{PM}_{1}$ to bulk nss-SO ${ }_{4}^{2-}$ ratio was 0.85 . The ratio exceeded 1.0 for some cases and, therefore, may be within the un- certainties of the analysis (Fig. 6a). The modeled ratio was also large because approximately $80 \%$ of the nss- $\mathrm{SO}_{4}^{2-}$ was mixed with submicron particles, such as ATK, ACM and AGR (Fig. 6b). The modeled median was 0.66, which was smaller than that observed, indicating that the modeled size distribution of nss- $\mathrm{SO}_{4}^{2-}$ may have been larger than that observed or that the proportions mixed with larger COR particles might have been overestimated. The features of the $\mathrm{NH}_{4}^{+}$ ratio were similar to those for nss- $\mathrm{SO}_{4}^{2-}$ because nss- $\mathrm{SO}_{4}^{2-}$ is a major counterpart of $\mathrm{NH}_{4}^{+}$. A range of $20-60 \%$ of T- $\mathrm{NH}_{4}^{+}$ existed in the gas phase in summer as $\mathrm{NH}_{3}$ because the temperature was high enough for $\mathrm{NH}_{4} \mathrm{NO}_{3}$ to evaporate and/or the amount of nss- $\mathrm{SO}_{4}^{2-}$ was not enough to consume $\mathrm{NH}_{3}$ gas to fix it to the aerosol phase as ammonium sulfate. Because the modeled nss- $\mathrm{SO}_{4}^{2-}$ and $\mathrm{NH}_{4}^{+}$were both underestimated, improving nss- $\mathrm{SO}_{4}^{2-}$ could also improve $\mathrm{NH}_{4}^{+}$.

The observed and modeled medians of the $\mathrm{PM}_{1}$ to $\mathrm{T}-\mathrm{NO}_{3}^{-}$ ratios were 0.054 and 0.035 , respectively, which were greater than one order of magnitude smaller than those for nss-SO ${ }_{4}^{2-}$ and $\mathrm{NH}_{4}^{+}$(Fig. 6e). Those ratios are approximately one order of magnitude larger than those for the sea-salt originated components $\mathrm{T}_{-}-\mathrm{Cl}^{-}$. This indicates that some fraction of nitrate is mixed with sea-salt particles as $\mathrm{NaNO}_{3}$ while some is mixed with submicron particles as $\mathrm{NH}_{4} \mathrm{NO}_{3}$. A more detailed discussion follows in Sect. 4.4.3.

The observed and modeled medians of the $\mathrm{PM}_{1}$ to T-Cl${ }^{-}$ ratios were one order of magnitude smaller than those for 

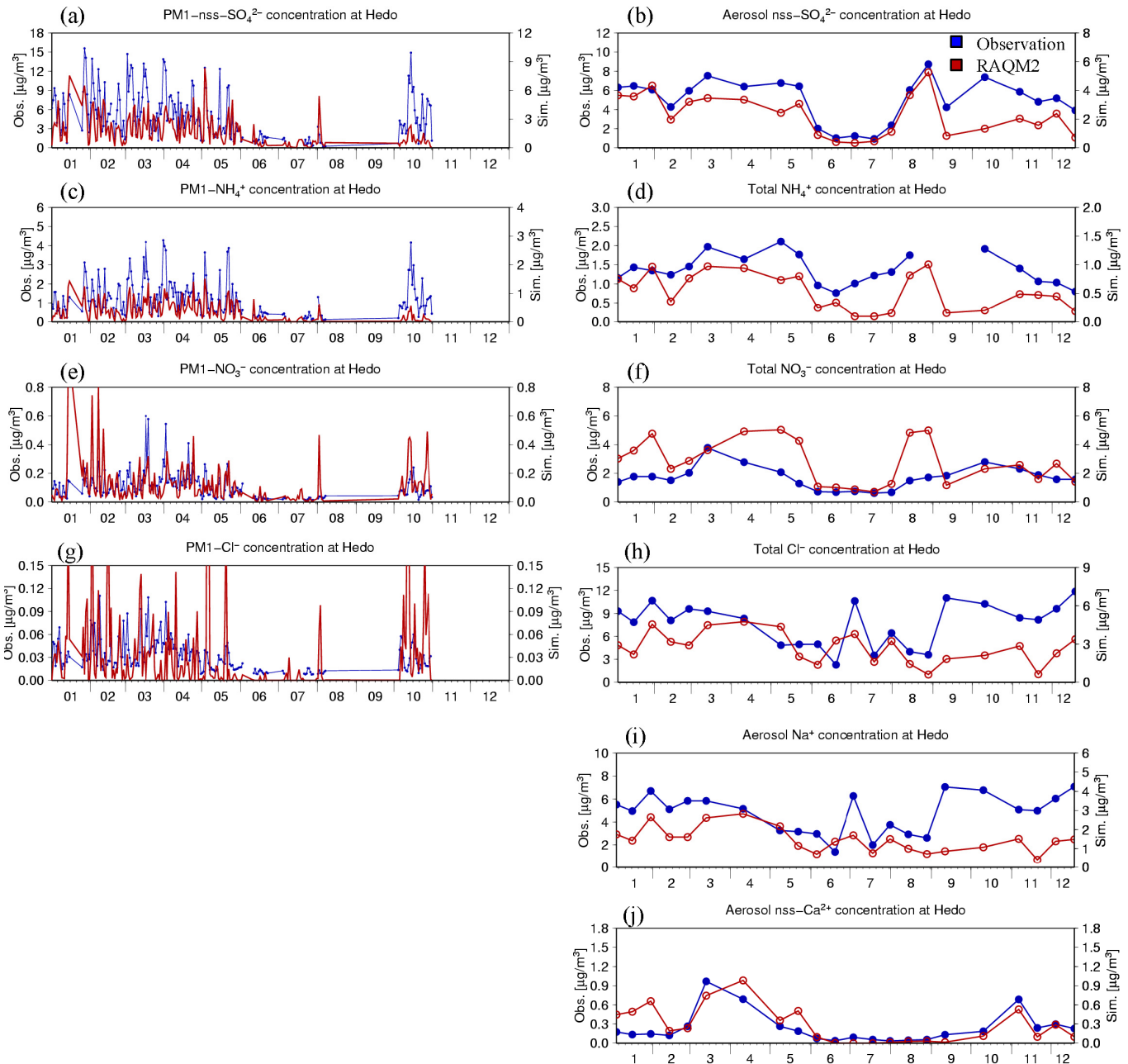

Fig. 5. (Left) Daily mean AMS measured (blue, left axis) and modeled (red, right axis) $\mathrm{PM}_{1}$ (a) $\mathrm{nss}_{-} \mathrm{SO}_{4}^{2-}$, (c) $\mathrm{NH}_{4}^{+}$, (e) $\mathrm{NO}_{3}^{-}$, and (g) $\mathrm{Cl}^{-}$ concentrations at Hedo (CHAAMS). (Right) The biweekly FP measured and modeled (b) nss-SO $\mathrm{SO}_{4}^{2-},(\mathbf{d}) \mathrm{T}^{-\mathrm{NH}_{4}^{+}}$, (f) $\mathrm{T}-\mathrm{NO}_{3}^{-},(\mathbf{h}) \mathrm{T}-\mathrm{Cl}^{-}$, (i) $\mathrm{Na}^{+}$, and $(\mathbf{j})$ nss-Ca ${ }^{2+}$ concentrations at Hedo (EANET).

T- $\mathrm{NO}_{3}^{-}$. Almost all (99.4\% on average) of the aerosol phase $\mathrm{Cl}^{-}$was mixed with COR particles. The modeled fractions of $\mathrm{HCl}$ gas showed a maximum in summer, with a value of $51 \%$. Because anthropogenic $\mathrm{HCl}$ emission was not considered in the current settings of RAQM2, the modeled T- $\mathrm{Cl}^{-}$ are all of sea salt origin. The temperature is high and the air is photochemically active in summer, so the $\mathrm{HNO}_{3}$ gas concentration is also high. $\mathrm{HNO}_{3}$ gas efficiently condensed onto sea-salt particles and expelled the $\mathrm{Cl}^{-}$into the gas phase by the chlorine deficit reaction (Eq. 26) in summer.

\subsubsection{Mixing type of sulfate}

Figure 7 illustrates the spatial distribution of mean concentrations and mixing types of sulfate in the lower atmosphere ( $<\sim 1000 \mathrm{~m}$; averages in 1 st to 7 th vertical grids). The seasonal trends of the nss- $\mathrm{SO}_{4}^{2-}$ mixing type were interesting
(Fig. $6 \mathrm{~b}$ and Fig. 7). Nss-SO ${ }_{4}^{2-}$ internally mixed with ATK + ACM was the greatest in summer (June to July; Fig. 7c and d). Because the air is cleaner in summer, there are fewer surface areas of pre-existing aerosols onto which the $\mathrm{H}_{2} \mathrm{SO}_{4}$ gas can condense, and new particle formation would occur more frequently. In contrast, in cold seasons, due to the abundance of preexisting aerosols including soot, $\mathrm{H}_{2} \mathrm{SO}_{4}$ gas was efficiently condensed onto the soot particles (AGR) (Fig. 7e and f). However, the current analysis could not prove the plausibility of the mixing type. For this proof, the results should be evaluated in the future by comparing them with soot mixing state measurements using a Volatility Tandem Differential Mobility Analyzer (VTDMA), a Single Particle Soot Photometer (SP2), or a Transmission Electron Microscope (TEM). The modeled nss-SO ${ }_{4}^{2-}$ was mixed with COR from $10-40 \%$. The crustal components in COR, such as $\mathrm{Na}^{+}$in sea-salt or $\mathrm{Ca}^{2+}$ in Asian dust, could be counterparts 

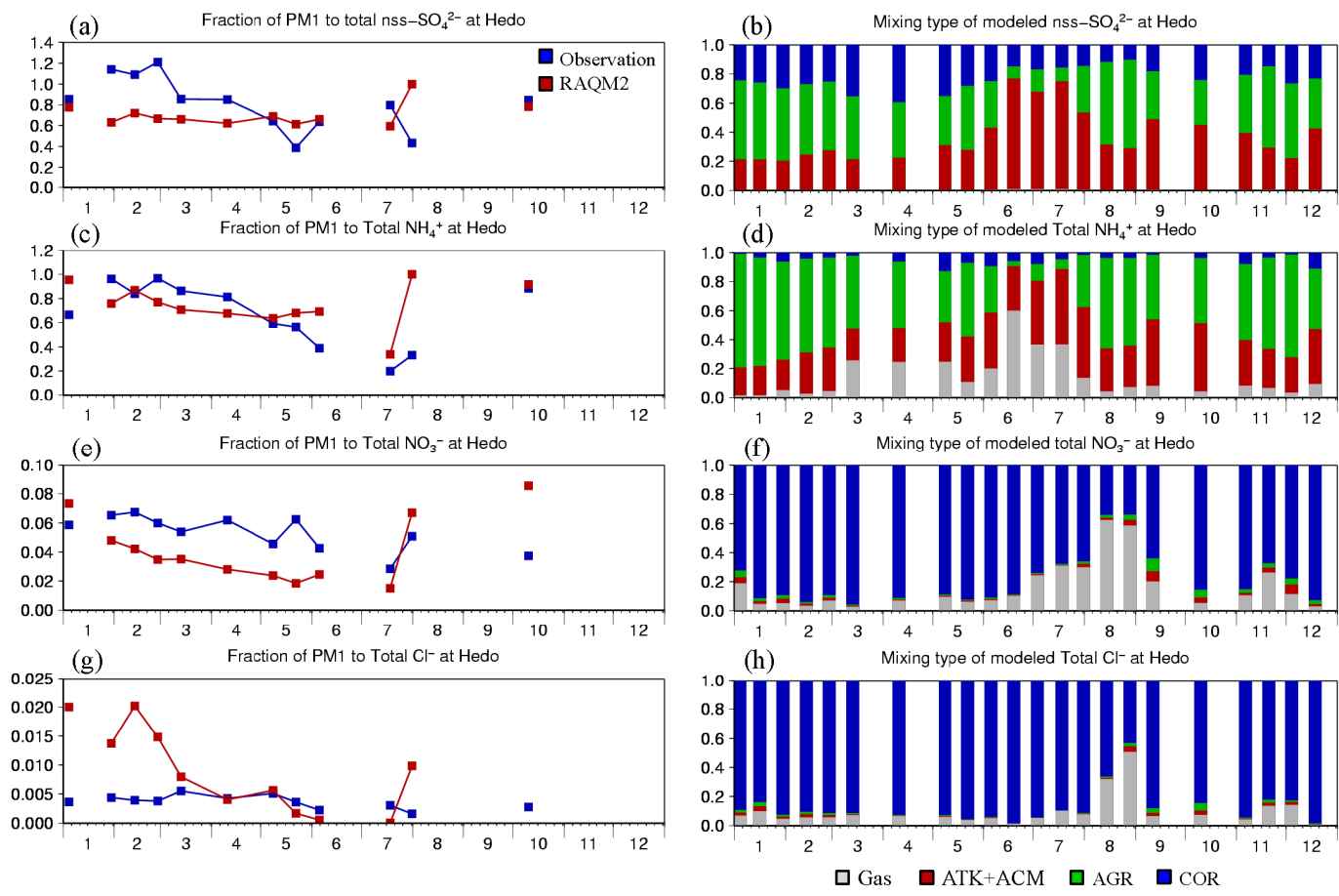

Fig. 6. (Left) Biweekly mean $\mathrm{PM}_{1}$ to total (gas plus aerosol) concentration ratios and (Right) the modeled fractions of gas phase (grey), ATK+ACM category (red), AGR category (green), and COR category (blue) aerosols of (a-b) nss-SO $\mathrm{SO}_{4}^{2-},(\mathbf{c}-\mathbf{d}) \mathrm{T}^{-\mathrm{NH}_{4}^{+}},(\mathbf{e}-\mathbf{f}) \mathrm{T}-\mathrm{NO}_{3}^{-}$, and (g-h) $\mathrm{T}_{-} \mathrm{Cl}^{-}$at Hedo.

of nss- $\mathrm{SO}_{4}^{2-}$. The proportions show maxima in spring from March to May (40\% in April is the peak), which coincides with the Asian dust transport period at Hedo (Fig. 5j). In the current setting of RAQM2, unfortunately, the dust particles are categorized as COR along with sea salt particles, so we cannot evaluate the nss- $\mathrm{SO}_{4}^{2-}$ mixed solely with Asian dust. Because the modeled nss- $\mathrm{SO}_{4}^{2-}$ was mixed with $\mathrm{COR}$, either with sea salt or Asian dust throughout the year, the modeled $\mathrm{PM}_{1}$ to bulk ratio was approximately 0.6 . The observed ratio also sometimes dropped to the modeled levels and to even less than half in May. Although certain discrepancies remained between the modeled and observed ratios, the modeled partitioning may not be so unrealistic.

\subsubsection{Mixing type of nitrate}

Figure 8 shows the spatial distribution of mean concentrations and mixing types of nitrate in the lower atmosphere. The mixing type of $\mathrm{NO}_{3}^{-}$at Hedo (Fig. 6f) was interesting when it was compared with that at Gosan, Jeju Island, Korea (shown in Fig. 1 as an arrow). The observed and modeled medians of the $\mathrm{PM}_{1}$ to $\mathrm{T}-\mathrm{NO}_{3}^{-}$ratios were 0.054 and 0.035 , respectively, more than an order of magnitude smaller than those for nss- $\mathrm{SO}_{4}^{2-}$ and $\mathrm{NH}_{4}^{+}$and one order of magnitude larger than those for $\mathrm{Cl}^{-}$. Therefore, the modeled T$\mathrm{NO}_{3}^{-}$partitioned into the gas phase or internally mixed with aerosols larger than $\mathrm{PM}_{1}$ and the observed were close to each other, at $96.5 \%$ and $94.6 \%$, respectively. Kajino and Kondo (2011) conducted a similar analysis for the case of the chemical component $\mathrm{PM}_{2.5} / \mathrm{PM}_{10}$ ratios at Gosan. They calculated that $53.7 \%$ of the modeled $\mathrm{NO}_{3}^{-}$was internally mixed with sea salt particles on average in March 2005. Their calculation was consistent with the observations, where the mean values of the modeled and observed $\mathrm{PM}_{2.5} / \mathrm{PM}_{10}$ ratios of $\mathrm{NO}_{3}^{-}$were both 0.66 . In the current simulation, $98 \%$ of the $\mathrm{NO}_{3}^{-}$was internally mixed with $\mathrm{COR}$ at the annual average at Hedo (Fig. 6f). The values of Fig. 8g is larger than those of Fig. 61 of Kajino and Kondo (2011) because the current figure is the average from the surface to a $1000 \mathrm{~m}$ height, while their paper showed those of the surface concentration, which contains a greater proportion of fresh sea-salt particles. There is a clear gradient in Fig. 8g from upstream near the continent $(\sim 50 \%)$ toward downwind over the ocean $(>90 \%)$.

The $\mathrm{NO}_{3}^{-}$mixing type difference at Gosan and Hedo was explained using the following equations:

$\mathrm{NH}_{3}(\mathrm{~g})+\mathrm{HNO}_{3}(\mathrm{~g}) \leftrightarrow \mathrm{NH}_{4} \mathrm{NO}_{3}(\mathrm{p})$

$\mathrm{NaCl}(\mathrm{p})+\mathrm{HNO}_{3}(\mathrm{~g}) \rightarrow \mathrm{NaNO}_{3}(\mathrm{p})+\mathrm{HCl}(\mathrm{g})$

Gosan is located approximately $700 \mathrm{~km}$ upwind of Hedo, toward the Asian continent. During long-range transport, $\mathrm{HNO}_{3}$ gas is produced via the photochemical oxidation of 


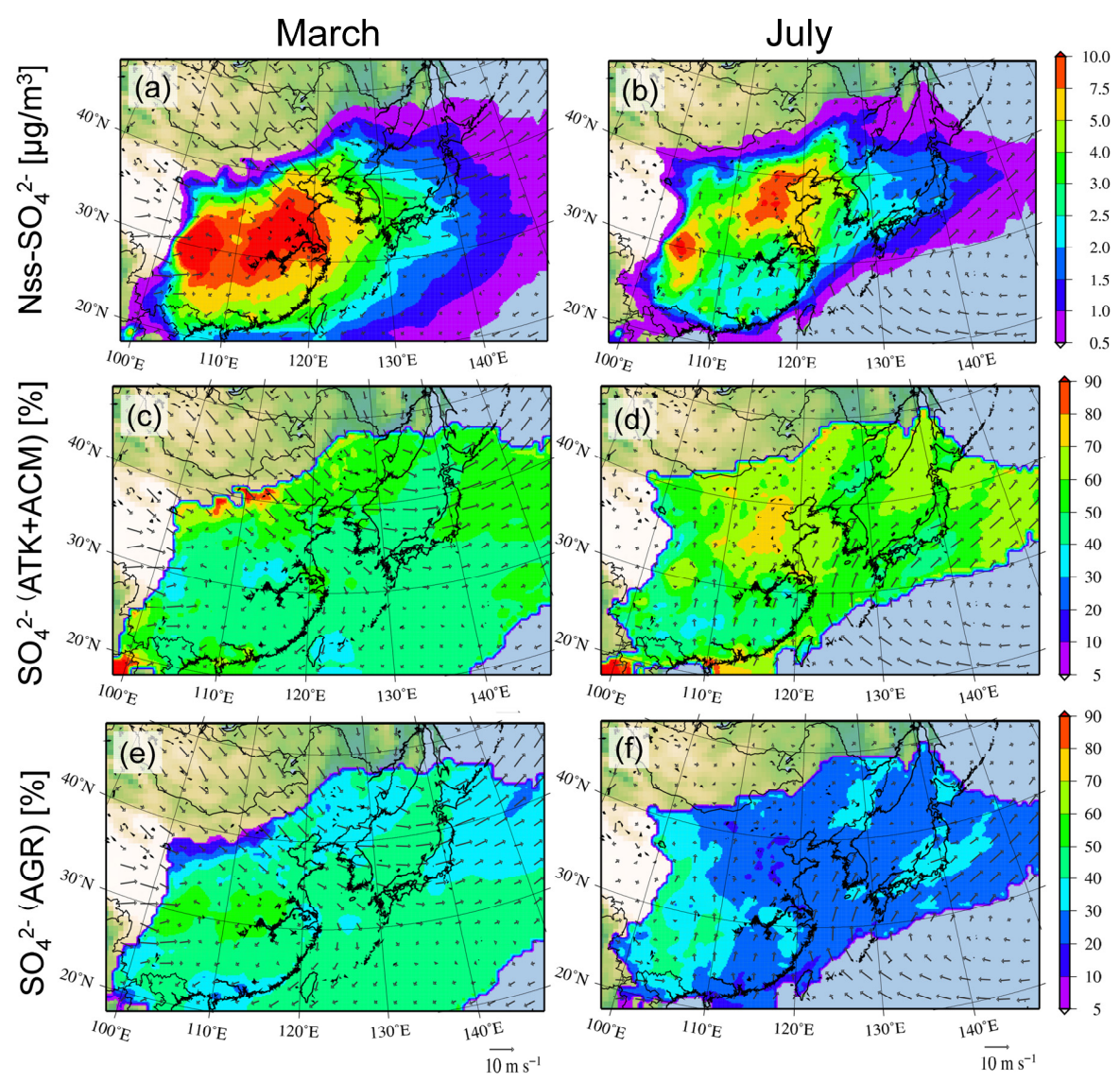

Fig. 7. Spatial distributions of mean concentrations and mixing types of sulfate in the lower atmosphere $(<\sim 1000 \mathrm{~m})$ in (left) March and (right) July: (a-b) sulfate concentration $\left(\mu \mathrm{m} \mathrm{m}^{-3}\right)$, (c-d) fraction of sulfate mixed with non-light-absorbing particles $($ ATK + ACM) $(\%)$, and (e-f) fraction of sulfate mixed with light-absorbing particles (AGR) (\%).

$\mathrm{NO}_{\mathrm{x}}$. The mass transfer coefficients for each aerosol mode of each category were nearly proportional to their total surface area for atmospheric aerosol size ranges (near the continuum regime). Over the continent, more than $90 \%$ of the $\mathrm{NO}_{3}^{-}$was mixed with submicron particles as $\mathrm{NH}_{4} \mathrm{NO}_{3}$ (Eq. 25; see NUC + AGR in Fig. 6j and k of Kajino and Kondo, 2011). We combined dust, sea-salt and anthropogenic $\mathrm{PM}_{10}$ particles together as the COR category; there are substantial proportions of nitrate mixed with COR over the continent in Fig. 8g, but those are not sea-salt particles. In contrast to the downwind regions of the continent over the ocean, the $\mathrm{HNO}_{3}$ gas produced during transport is more efficiently condensed onto sea salt particles as the sea salt surface area becomes large. The reaction of Eq. (26), occurring on/in the sea salt particles, also promotes the $\mathrm{HNO}_{3}$ condensation onto sea salt, forming $\mathrm{NaNO}_{3}$. Although the $\mathrm{HNO}_{3}$ gas production during transport is less significant, the reaction Eq. (26) itself may promote the evaporation of $\mathrm{HNO}_{3}$ gas in Eq. (25) because it is a reversible reaction. In this case, the $\mathrm{NO}_{3}^{-}$in submicron particles might convert to sea salt particles. The fractions of nitrate with COR are predominant all over the ocean (>80\%) in summer (Fig. $8 \mathrm{~h}$ ), as the temperature is higher and the fraction of $\mathrm{HNO}_{3}$ gas becomes larger (Eq. 25), which promotes the reaction in Eq. (26).

The mixing type of $\mathrm{NO}_{3}^{-}$may be important for the size distribution of aerosols and its light scattering property. Although the same amounts of aerosol $\mathrm{NO}_{3}^{-}$existed in the air, $\mathrm{HNO}_{3}$ condensed onto submicron particles forming $\mathrm{NH}_{4} \mathrm{NO}_{3}$ uptakes water and enhances the particle size efficiently and alters the light scattering properties. However, $\mathrm{HNO}_{3}$ condensed onto sea-salt particles may not alter the particle sizes and optical properties as significantly. This is because $\mathrm{HNO}_{3}$ condensed onto sea-salt expels $\mathrm{HCl}$ at the same time, the water uptake property may not change much, and the size increase ratio will be smaller than that for submicron particles, as the sea salt particles are larger.

\subsubsection{Mixing type of soot aggregate and soot-coarse mode particle mixtures}

Even though the simulated mixing states of soot and sootCOR mixtures were not evaluated, we show some examples that are important in aspects of aerosol-radiation-cloud 

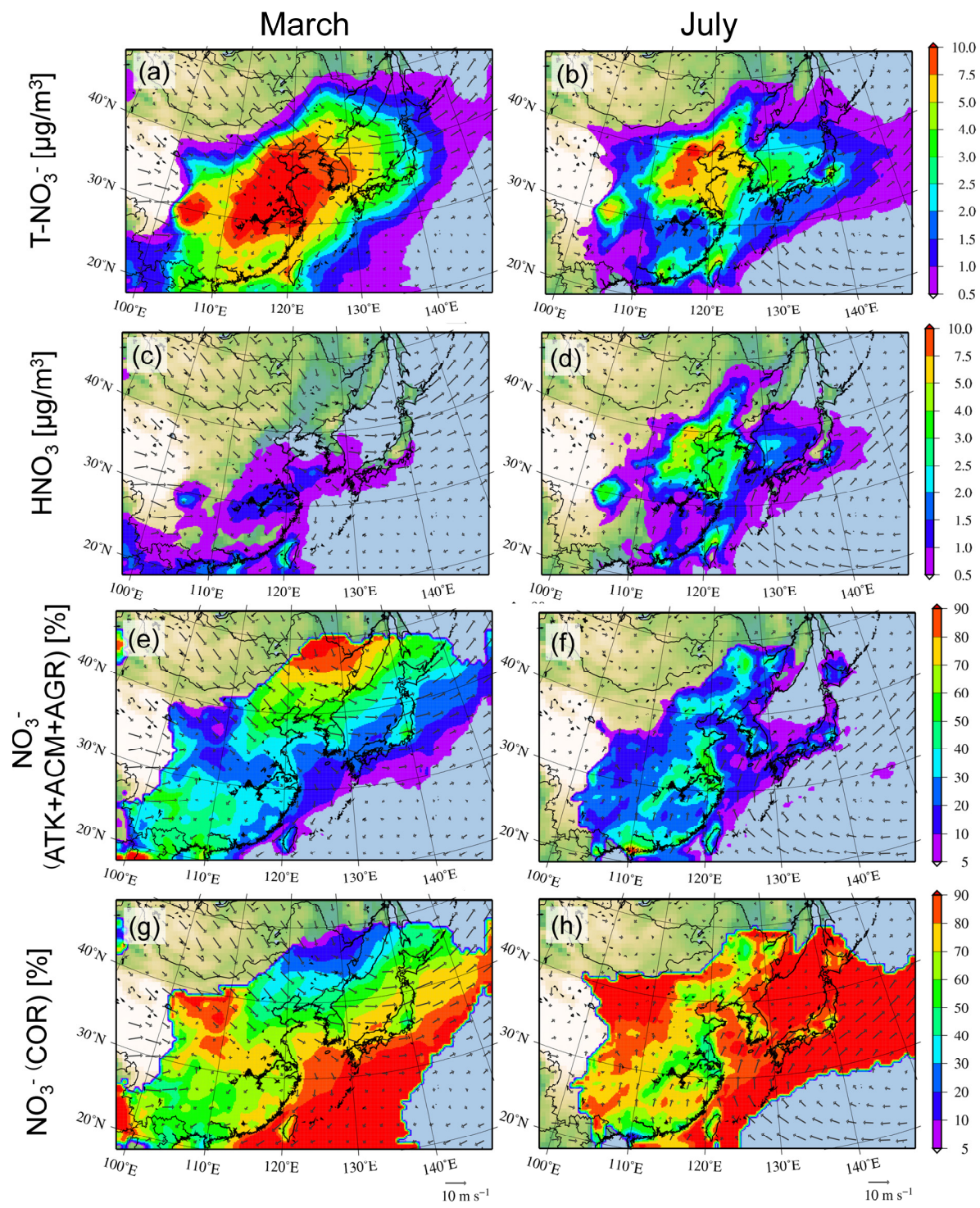

Fig. 8. Spatial distributions of the mean concentrations and mixing types of nitrate in the lower atmosphere $(<\sim 1000 \mathrm{~m})$ in $($ left $)$ March and (right) July: (a-b) total-nitrate (gas plus aerosol) concentration $\left(\mu \mathrm{m} \mathrm{m}^{-3}\right)$, (c-d) nitric acid gas concentration $\left(\mu \mathrm{m} \mathrm{m}^{-3}\right),(\mathbf{e}-\mathbf{f})$ fraction of nitrate mixed with submicron particles (ATK + ACM + AGR) $(\%)$, and (g-h) fraction of nitrate mixed with coarse mode particles $(\mathrm{COR})$ $(\%)$.

interaction. Figure 9 shows the mean black carbon (BC) concentration in AGR, the total dry mass to $\mathrm{BC}$ mass ratio, and the total wet mass to $\mathrm{BC}$ mass ratio. The SP2 measured shell/core diameter ratio in the Asian continental outflow was approximately 1.6 (Shiraiwa et al., 2008), so the mass ratio could be approximately 4 . Our simulated values could be significantly overestimated, approximately $5-10$ over the continent to 15-20 over the ocean (Fig. 9c and d). The hygroscopic components mixed with AGR were simulated to uptake water approximately 3-4 times the original dry mass.

Figure 10 shows the mean number concentrations of soot aggregate (AGR), coarse mode particles (COR) and the num- ber of AGR particles collided with COR particles $\left(M_{0}^{\mathrm{AGR}}\right.$ in Table 2). As discussed in Sect. 2.2.4, $M_{0}^{\mathrm{AGR}}$ does not express the number of AGR-COR aggregates. The coalescence efficiency may not be unity, and one COR particle can be attached to several AGR particles. In the simulation, the $M_{0}^{\mathrm{AGR}}$ were comparable to the $M_{0}$ of COR particles $(\sim 1-10$ particles $\mathrm{cm}^{-3}$ ) when the $M_{0}$ of AGR are 2-3 orders of magnitude larger $\left(\sim 1000\right.$ particles $\left.\mathrm{cm}^{-3}\right)$ and the $\mathrm{BC}$ mass concentrations are larger than $2-5 \mu \mathrm{g} \mathrm{m}^{-3}$. When the number concentration is low in summer (Fig. 10b) due to the lower emission flux and larger convection and turbulent mixing, 

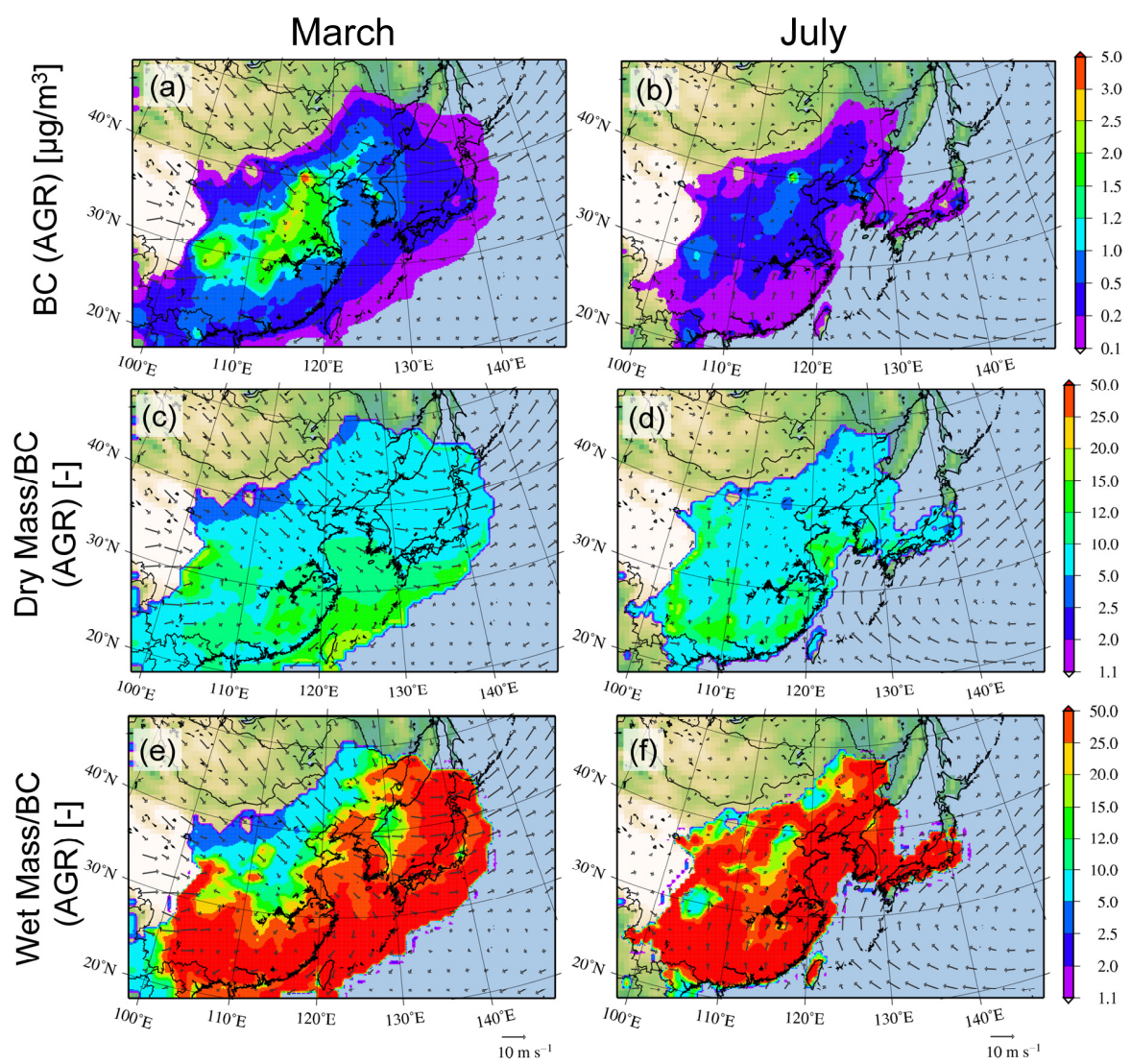

Fig. 9. Spatial distributions of the mean concentrations and mixing types of black carbon in the lower atmosphere $(<\sim 1000 \mathrm{~m})$ in $($ left $)$ March and (right) July. (a-b) Black carbon concentration $\left(\mu \mathrm{m} \mathrm{m}^{-3}\right),(\mathbf{c}-\mathbf{d})$ dry mass to black carbon mass ratio $(-)$, and $(\mathbf{e}-\mathbf{f})$ wet mass to black carbon mass ratio $(-)$.

the probability of collision between AGR and COR particles could be significantly lower (Fig. 10f).

\section{Conclusions}

A new aerosol chemical transport model, the Regional Air Quality Model 2 (RAQM2), was developed to simulate Asian air quality. We implemented a simple version of a triplemoment modal aerosol dynamics model (MADMS; Kajino, 2011) and achieved a completely dynamic (non-equilibrium) solution of gas-to-particle mass transfer over a wide range of aerosol diameters, from $1 \mathrm{~nm}$ to super- $\mu \mathrm{m}$. To consider a variety of atmospheric aerosol properties, the category approach (Kajino and Kondo, 2011) is utilized. In RAQM2, aerosols are distributed into four categories: (1) particles in the Aitken mode (ATK), (2) soot-free particles in the accumulation mode (ACM), (3) soot aggregates (AGR) and (4) particles in the coarse mode (COR). A regional-scale simulation $(\Delta x=60 \mathrm{~km})$ was performed for the entire year of 2006 covering the northeast Asian region. The modeled size distributions $\left(\mathrm{PM}_{2.5} / \mathrm{PM}_{10}\right.$ of the total weight and $\mathrm{PM}_{1} /$ bulk ratios of chemical components) agreed quantitatively with those observed at the EANET and CHAAMS sites. We concluded that our predictions of aerosol mixing types (ATK, ACM, AGR and COR) of inorganic aerosol components such as nss- $\mathrm{SO}_{4}^{2-}, \mathrm{NH}_{4}^{+}, \mathrm{NO}_{3}^{-}$, and $\mathrm{Cl}^{-}$were consistent with those in nature.

The modeled mixing types of the chemical components were found to be interesting. The Nss- $\mathrm{SO}_{4}^{2-}$ internally mixed with ATK + ACM was greatest in summer (June to July). Because the air is cleaner in summer, there are less surface areas of preexisting aerosols onto which $\mathrm{H}_{2} \mathrm{SO}_{4}$ gas can condense; thus, new particle formation would occur more frequently. In contrast, in cold seasons, due to the abundance of pre-existing aerosols including soot, $\mathrm{H}_{2} \mathrm{SO}_{4}$ gas was efficiently condensed onto the soot particles (AGR). To prove the results, the modeled mixing type should be evaluated in the future by comparing it with measurements of the soot mixing state using Volatility Tandem Differential Mobility Analyzer (VTDMA), Single Particle Soot Photometer (SP2), or Transmission Electron Microscope (TEM) analysis. The simulated total dry mass to black carbon (BC) mass ratio was approximately $5-10$ over the continent and $15-20$ over the ocean, which is significantly larger than the previous 

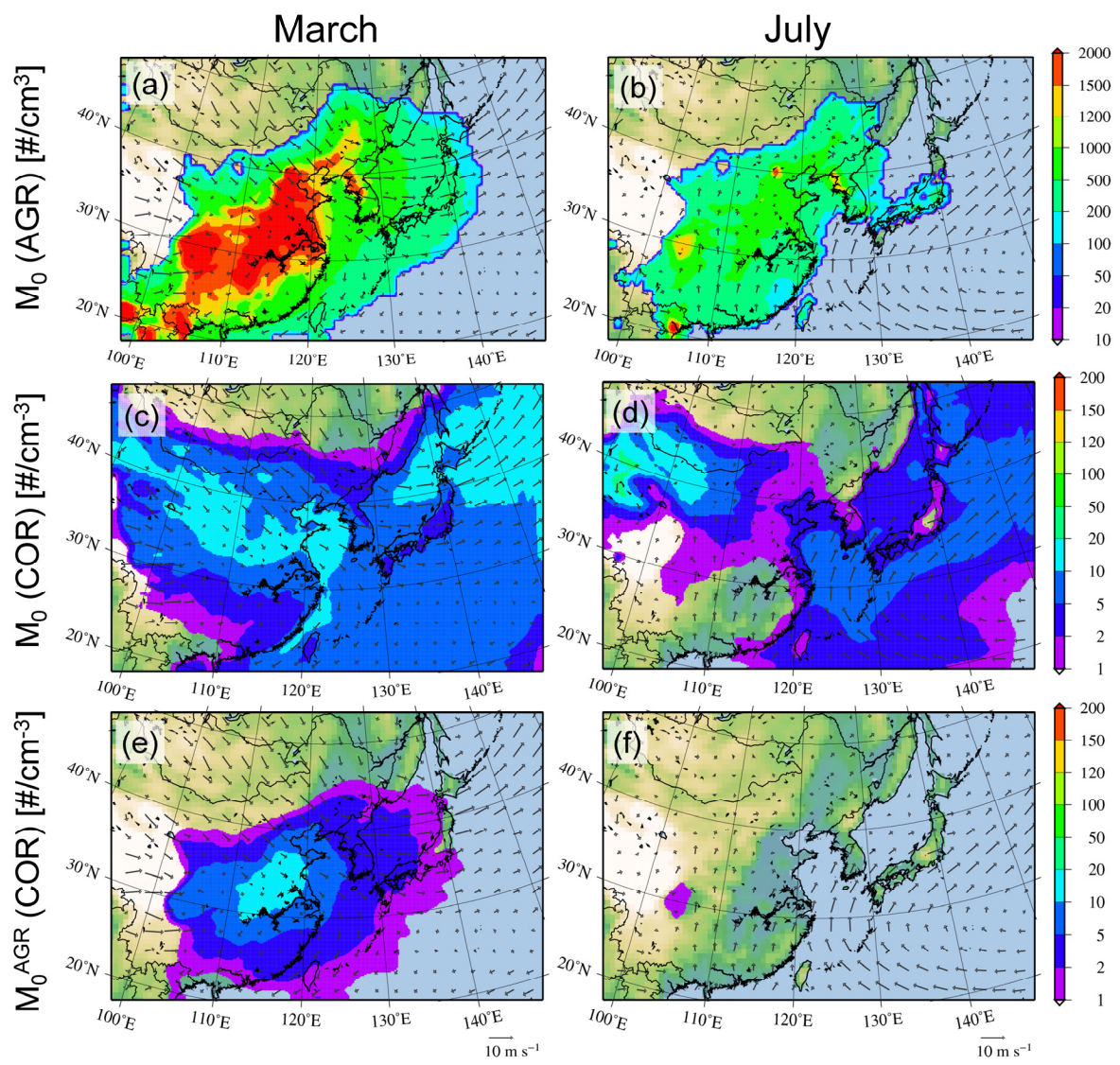

Fig. 10. Spatial distributions of mean number concentrations in (left) March and (right) July of (a-b) soot (particles $\left.\mathrm{cm}^{-3}\right)$, (c-d) coarse mode particles (dust, sea-salt, and anthropogenic $\left.\mathrm{PM}_{10}\right)\left(\right.$ particles $\mathrm{cm}^{-3}$ ) and $(\mathbf{e}-\mathbf{f})$ the number of soot aggregate particles collided with coarse mode particles (particles $\mathrm{cm}^{-3}$ ).

Asian continental outflow measurement $(\sim 4)$. Further efforts are necessary to obtain the consistent features of Asian aerosol properties. The number of AGR particles collided with COR particles was also simulated in this study and could be comparable to the number COR concentration $(\sim 1-$ 10 particles $\mathrm{cm}^{-3}$ ) when the AGR number concentrations were $2-3$ orders of magnitude larger $\left(\sim 1000\right.$ particles $\left.\mathrm{cm}^{-3}\right)$ in the cold seasons. When the AGR concentrations were low in summer, the probability of collision between AGR and COR particles could be significantly lower.

The difference in the mixing type of $\mathrm{NO}_{3}^{-}$at Hedo and Gosan was interesting. Ninety-eight percent of the modeled $\mathrm{NO}_{3}^{-}$was internally mixed with $\mathrm{COR}$ at Hedo, whereas $53.7 \%$ of the $\mathrm{NO}_{3}^{-}$was internally mixed with sea salt particles at Gosan (Kajino and Kondo, 2011). The modeled values were consistent with the observed $\mathrm{NO}_{3}^{-} \mathrm{PM}_{2.5} / \mathrm{PM}_{10}$ ratio at Gosan and the $\mathrm{PM}_{1} / \mathrm{T}-\mathrm{NO}_{3}^{-}$ratio at Hedo. Gosan is located upwind of Hedo toward the Asian continent. To the downwind regions of the continent over the ocean, the $\mathrm{HNO}_{3}$ gas produced during transport is more efficiently condensed onto sea salt particles as the proportion of the sea salt surface area to the total aerosol surface area becomes large. The chlo- rine deficit reaction on the sea salt particles promoted the condensation of $\mathrm{HNO}_{3}$. This reaction decreases the $\mathrm{HNO}_{3}$ gas concentration, resulting in evaporation of $\mathrm{NH}_{4} \mathrm{NO}_{3}$ from submicron particles. This conversion of nitrate in submicron particles to sea salt particles might occur during transport.

The aerosol mixing type, in addition to number, size, and chemistry, is a key parameter for the light scattering and absorbing properties. Further investigation is needed by comparing the results with the aerosol optical thickness (AOT) or single scattering albedo (SSA) observations to accurately assess the aerosol-radiation interaction processes. The aerosol mixing type is also an essential parameter for predicting the $\mathrm{CCN}$ and IN activities of aerosols. To better understanding the importance of those parameters in the whole aerosolcloud-radiation interaction systems, the online coupling of meteorology and chemistry models is indispensable in the near future.

The current model is computationally efficient in a sense that even though we consider the mixing types, we need only a few transport variables because we used a modal approach, which is less accurate compared to a sectional approach. Our approach is also efficient in aerosol process 
modeling because even though we used 1-s time steps to resolve the simultaneous nucleation, condensation, and coagulation processes of nano-particles, we adopted a larger time step to solve the multi-component thermodynamic equilibrium states, which is computationally expensive. One-box simulations with several sensitivity runs (operator splitting, time splitting, number of modes or categories, or modal vs. sectional approaches) will be useful to optimize the current method in terms of accuracy and efficiency.

Acknowledgements. This research was promoted by the Fundamental Research Budget of the Meteorological Research Institute of Japan, "Studies on Atmospheric Aerosol Properties and Processes". The study was partly supported by the Environment Research and Technology Development Fund (Project No. B-0905 and A-1101) of the Ministry of the Environment of Japan and the Ministry of Education, Science, Sports and Culture (MEXT) Grant-in-Aid for Scientific Research (B), 23310018, 2011.

Edited by: A. Nenes

\section{References}

Abdul-Razzak, H. and Ghan, S. J.: A parameterization of aerosol activation. 2. Multiple aerosol typles, J. Geophys. Res., 105, 68376844, 2000.

An, J., Ueda, H., Wang, Z., Matsuda, K., Kajino, M., and Cheng, X.: Simulations of monthly mean nitrate concentrations in precipitation, Atmos. Environ., 36, 4159-4171, 2002.

An, J., Ueda, H., Matsuda, K. Hasome, H., and Iwata, M.: Simulated impacts of $\mathrm{SO}_{2}$ emissions from the Miyake volcano on concentration and deposition of sulfur oxides in September and October of 2000, Atmos. Environ., 37, 3039-3046, 2003.

Binkowski, F. S. and Shankar, U.: The regional particulate model: 1. Model description and preliminary results, J. Geophys. Res., 100, 26191-26209, doi:10.1029/95JD02093, 1995.

Byun, D. and Schere, K. L.: Review of the governing equations, computational algorithms, and other components of the Models3 Community Multiscale Air Quality (CMAQ) Modeling System, Appl. Mech. Rev., 59, 51-77, 2006.

Carter, W.: Documentation of the SAPRC-99 chemical mechanism for VOC reactivity assessment. Final report to California Air Resources Board, Rep. 92-329, Univ. of Calif., Riverside, 8 May, 2000.

Carlton, A. G., Turpin, B. J., Altieri, K. E., Seitzinger, S., Reff, A., Lim, H.-J., and Ervens, B.: Atmospheric oxalic acid and SOA production from glyoxal: Results of aqueous photooxidation experiment, Atmos. Environ., 41, 7588-7602, 2007.

Carmichael, G. R., Sakurai, T., Streets, D., Hozumi, Y., Ueda, H., Park, S. U., Fung, C., Han, Z., Kajino, M., Engardt, M., Bannet, C., Hayami, H., Sartelet, K., Holloway, T., Wang, Z., Kannari, A., Fu, J., Matsuda, K., Thongboonchoo, N., and Amann, M.: MICS-Asia II: the model intercomparison study for Asia phase II methodology and overview of findings, Atmos. Environ., 42, 3468-3490, 2008.

Chen, F. and Dudhia, J.: Coupling an advanced land-surface/ hydrology model with the Penn State/ NCAR MM5 modeling system. Part I: Model description and implementation, Mon. Weather Rev., 129, 569-585, 2001.

Clarke, A. D., Shinozuka, Y., Kapustin, V. N., Howell, S., Huebert, B., Doherty, S., Anderson, T., Covert, D., Anderson, J., Hua, X., Moore II, K. G., McNaughton, C., Carmichael, G. R., and Weber, R.: Size distributions and mixtures of dust and black carbon aerosol in Asian outflow: Physicochemistry and optical properties, J. Geophys. Res., 109, D15S09, doi:10.1029/2003JD004378, 2004.

Clarke, A. D., Owens, S. R., and Zhou, J.: An ultrafine sea-salt flux from breaking waves: Implications for cloud condensation nuclei in the remote marine atmosphere, J. Geophys. Res., 111, D06202, doi:10.1029/2005JD006565, 2006.

Deushi, M. and Shibata, K.: Development of an MRI ChemistryClimate Model ver.2 for the study of tropospheric and strarospheric chemistry, Papers in Meteor. Geophys., 62, 1-46, 2011.

DOE: Handbook of methods for the analysis of the various parameters of the carbon dioxide system in sea water, Version 2, edited by: Dickson, A. G. and Goyet, C., ORNL/CDIAC-74, 1994.

Dudhia, J.: Numerical study of convection observed during the winter monsoon experiment using a mesoscale two-dimensional model, J. Atmos. Sci., 46, 3077-3107, 1989.

Edney, E. O., Kleindienst, T. E., Lewandowski, M., and Offenberg, J. H.: Updated SOA chemical mechanism for the Community Multiscale Air Quality model, EPA 600/X-07/025, US Environ. Prot. Agency, Durham, NC, 2007.

Foley, K. M., Roselle, S. J., Appel, K. W., Bhave, P. V., Pleim, J. E., Otte, T. L., Mathur, R., Sarwar, G., Young, J. O., Gilliam, R. C., Nolte, C. G., Kelly, J. T., Gilliland, A. B., and Bash, J. O.: Incremental testing of the Community Multiscale Air Quality (CMAQ) modeling system version 4.7, Geosci. Model Dev., 3, 205-226, doi:10.5194/gmd-3-205-2010, 2010.

Fountoukis, C. and Nenes, A.: ISORROPIA II: a computationally efficient thermodynamic equilibrium model for $\mathrm{K}^{+}-\mathrm{Ca}^{2+}-\mathrm{Mg}^{2+}-\mathrm{NH}_{4}^{+}-\mathrm{Na}^{+}-\mathrm{SO}_{4}^{2-}-\mathrm{NO}_{3}^{-}-\mathrm{Cl}^{-}-\mathrm{H}_{2} \mathrm{O}$ aerosols, Atmos. Chem. Phys., 7, 4639-4659, doi:10.5194/acp7-4639-2007, 2007.

Fuchs, N. A.: The Mechanics of Aerosols, Pergamon Press, Oxford, 1964.

Giglio, L., Randerson, J. T., van der Werf, G. R., Kasibhatla, P. S., Collatz, G. J., Morton, D. C., and DeFries, R. S.: Assessing variability and long-term trends in burned area by merging multiple satellite fire products, Biogeosciences, 7, 1171-1186, doi:10.5194/bg-7-1171-2010, 2010.

Grell, G. A. and Devenyi, D.: A generalized approach to parameterizing convection combining ensemble and data assimilation techniques, Geophys. Res. Lett., 20, 1693, doi:10.1029/2002GL015311, 2002.

Guazzotti, S. A., Coffee, K. R., and Prather, K. A.: Continuous measurements of size-resolved particle chemistry during INDOEXIntensive Field Phase 99, J. Geophys. Res., 106, 28607-28628, 2001.

Guenther, A., Karl, T., Harley, P., Wiedinmyer, C., Palmer, P. I., and Geron, C.: Estimates of global terrestrial isoprene emissions using MEGAN (Model of Emissions of Gases and Aerosols from Nature), Atmos. Chem. Phys., 6, 3181-3210, doi:10.5194/acp-63181-2006, 2006.

Han, Z.: A regional air quality model: evaluation and simulation of $\mathrm{O}_{3}$ and relevant gaseous species in East Asia during spring 2001, 
Environ., Modell. Softw., 22, 1328-1336, 2007.

Han, Z., Ueda, H., Matsuda, K., Zhang, R., Arao, K., Kanai, Y., and Hasome, H.: Model study on particle size segregation and deposition during Asian dust events in March 2002, J. Geophys. Res., 109, D19205, doi:10.1029/2004JD004920, 2004.

Han, Z., Ueda, H., and Matsuda, K.: Model study of the impact of biogenic emission on regional ozone and effectiveness of emission reduction scenarios over eastern China, Tellus B, 53, 171191,2005

Han, Z., Ueda, H., and Sakurai, T.: Model study on acidifying wet deposition in East Aisa during wintertime, Atmos. Environ., 40, 2360-2373, 2006.

Hirsikko, A., Nieminen, T., Gagné, S., Lehtipalo, K., Manninen, H. E., Ehn, M., Hõrrak, U., Kerminen, V.-M., Laakso, L., McMurry, P. H., Mirme, A., Mirme, S., Petäjä, T., Tammet, H., Vakkari, V., Vana, M., and Kulmala, M.: Atmospheric ions and nucleation: a review of observations, Atmos. Chem. Phys., 11, 767798, doi:10.5194/acp-11-767-2011, 2011.

Hong, S.-Y. and Lin, J.-O. J.: The WRF single-moment 6-class microphysics scheme (WSM6), J. Korean Meteor. Soc., 42, 129151,2006

Ishikawa, H.: Mass-consistent wind model as a meteorological preprocessor for tracer transport models, J. Appl. Meteorol., 33, 733-743, 1994.

Jacobson, M. Z. and Ginnebaugh, D. L.: Global-through-urban nested three-dimensional simulation of air pollution with a 13,600-reaction photochemical mechanism, J. Geophys. Res., 115, D14304, doi:10.1029/2009JD013289, 2010.

Janjic, Z. I.: Nonsingular implementation of the Mellor-Yamada level 2.5 scheme in the NCEP Medo model, Off. Note, 437, 61 pp., Natl. Cent. for Environ. Predict., Camp Springs, Md.

Kajino, M.: MADMS: Modal Aerosol Dynamics model for multiple Modes and fractal Shapes in the free-molecular and nearcontinuum regimes, J. Aerosol Sci., 42, 224-248, 2011.

Kajino, M. and Kondo, Y.: EMTACS: Development and regionalscale simulation of a size, chemical, mixing type, and soot shape resolved atmospheric particle model, J. Geophys. Res., 116, D02303, doi:10.1029/2010JD015030, 2011.

Kajino, M., Ueda, H., Satsumabayashi, H., and An, J.: Impacts of the eruption of Miyakejima Volcano on air quality over far east Asia, J. Geophys. Res., 109, D21204, doi:10.1029/2004JD004762, 2004.

Kajino, M., Ueda, H., Satsumabayashi, H., and Han, Z.: Increase in nitrate and chloride deposition in east Asia due to increased sulfate associated with the eruption of Miyakejima Volcano, J. Geophys. Res., 110, D18203, doi:10.1029/2005JD005879, 2005.

Kajino, M., Ueda, H., and Nakayama, S.: Secondary acidification: Changes in gas-aerosol partitioning of semivolatile nitric acid and enhancement of its deposition due to increased emission and concentration of $\mathrm{SO}_{\mathrm{x}}$, J. Geophys. Res., 113, D03302, doi:10.1029/2007JD008635, 2008.

Kang, J.-Y., Yoon, S.-C., Shao, Y., and Kim, S.-W.: Comparison of vertical dust flux by implementing three dust emission schemes in WRF/Chem, J. Geophys. Res., 116, D09202, doi:10.1029/2010JD014649, 2011.

Katata, G., Nagai, H., Wrzesinsky, T., Klemm, O., Eugster, W., and Burkard, R.: Development of a land surface model including cloud water deposition on vegetation, J. Appl. Meteor. Climatol., 47, 2129-2146, 2008
Katata, G., Nagai, H., Zhang, L., Held, A., Serça, D., and Klemm, O.: Development of an atmosphere-soil-vegetation model for investigation of radioactive materials transport in the terrestrial biosphere, P. Nucl. Sci. Technol., 2, 530-537, 2011.

Kirsch, A. A. and Fuchs, N. A.: Studies on fibrous aerosol filters. III Diffusional deposition of aerosols in fibrous filters, Ann. Occup. Hyg., 11, 299-304, 1968.

Kuang, C., McMurry, P. H., McCormick, A. V., and Eisele, F. L.: Dependence of nucleation rates on sulfuric acid vapor concentration in diverse atmospheric locations, J. Geophys. Res., 113, D10209, doi:10.1029/2007JD009253, 2008

Kulmala, M. and Kerminen, V.-M.: On the formation and growth of atmospheric nanoparticles, Atmos. Res., 90, 132-150, 2008.

Kurokawa, J., Ohara, T., Uno, I., Hayasaki, M., and Tanimoto, H.: Influence of meteorological variability on interannual variations of springtime boundary layer ozone over Japan during 19812005, Atmos. Chem. Phys., 9, 6287-6304, doi:10.5194/acp-96287-2009, 2009.

Lin, Y.-L., Farley, R. D., and Orville, H. D.: Bulk parameterization of the snow field in a cloud model, J. Clim. Appl. Meteorol., 22, 1065-1092, 1983.

Lohmann, U. and Diehl, K.: Sensitivity studies of the importance of dust ice nuclei for the indirect aerosol effect on stratiform mixedphase clouds, J. Atmos. Sci., 63, 968-982, 2010.

Madronich, S.: Photodissociation in the atmosphere: 1. Actinic flux and the effects of ground reflections and clouds, J. Geophys. Res., 92, 9740-9752, doi:10.1029/JD092iD08p09740, 1987.

Mlawer, E. J., Taubman, S. J., Brown, P. D., Iacono, M. J., and Clough, S. A.: Radiative transfer for inhomogeneous atmosphere, RRTM, a validated correlated-k model for the long wave, J. Geophys. Res., 102, 16663-16682, doi:10.1029/97JD00237, 1997.

Myneni, R. B., Hoffman, S., Knyazikhin, Y., Privette, J. L., Glassy, J., Tian, Y., Wang, Y., Song, X., Zhang, Y., Smith, G. R., Lotsch, A., Friedl, M., Morisette, J. T., Votava, P., Nemani, R. R., and Running S. W.: Global products of vegetation leaf area and fraction absorbed PAR from year one of MODIS data, Remote Sens. Environ., 83, 214-231, 2002.

Nagashima, T., Ohara, T., Sudo, K., and Akimoto, H.: The relative importance of various source regions on East Asian surface ozone, Atmos. Chem. Phys., 10, 11305-11322, doi:10.5194/acp10-11305-2010, 2010.

Ohara, T., Akimoto, H., Kurokawa, J., Horii, N., Yamaji, K., Yan, X., and Hayasaka, T.: An Asian emission inventory of anthropogenic emission sources for the period 1980-2020, Atmos. Chem. Phys., 7, 4419-4444, doi:10.5194/acp-7-4419-2007, 2007.

Pagels, J., Khalizov, A. F., McMurry, P. H., and Zhang, R. Y.: Processing of soot by controlled sulphuric acid and water condensation - Mass and mobility relationship, Aerosol Sci. Technol., 43, 629-640, 2009.

Peters, K. and Eiden, R.: Modelling the dry deposition velocity of aerosol particles to a spruce forest, Atmos. Environ., 26A, 25552564, 1992.

Petroff, A. and Zhang, L.: Development and validation of a size-resolved particle dry deposition scheme for application in aerosol transport models, Geosci. Model Dev., 3, 753-769, doi:10.5194/gmd-3-753-2010, 2010. 
Pleim, J. E. and Chang, J. S.: A non-local closure model for vertical mixing in the convective boundary layer, Atmos. Environ., 26A, 965-981, 1992.

Pruppacher, H. R. and Klett, J. D.: Microphysics of Clouds and Precipitation, Kluwer Acad., Norwell, Mass., 1997.

Sekiyama, T. T., Tanaka, T. Y., Shimizu, A., and Miyoshi, T.: Data assimilation of CALIPSO aerosol observations, Atmos. Chem. Phys., 10, 39-49, doi:10.5194/acp-10-39-2010, 2010.

Shiraiwa, M., Kondo, Y., Moteki, N., Takegawa, N., Sahu, L. K., Takami, A., Hatakeyama, S., Yonemura, S., and Blake, D. R.: Radiative impact of mixing state of black carbon aerosol in Asian outflow, J. Geophys. Res., 11, D24210, doi:10.1029/2008JD010546, 2008.

Skamarock, W. C., Klemp, J. B., Dudhia, J., Gill, D. O., Barker, D. M., Duda, M. G., Huang, X. Y., Wang, W., and Powers, J. G.: A description of the advanced research WRF version 3, Tech. Note, NCAR/TN 475+STR, 125 pp., Natl. Cent. for Atmos. Res., Boulder, Colo., 2008.

Song C. H. and Carmichael, G. R.: A 3D modeling investigation of the evolution processes of dust and sea-salt particles in east Asia, J. Geophys. Res., 106, 18131-18154, 2001.

Sudo, K. and Akimoto, H.: Global source attribution of tropospheric ozone: Long-range transport from various source regions, J. Geophys. Res., 112, D12302, doi:10.1029/2006JD007992, 2007.

Takami, A., Miyoshi, T., Shimono, A., Kaneyasu, N., Kato, S., Kajii, Y., and Hatakeyama, S.: Transport of anthropogenic aerosols from Asia and subsequent chemical transformation, J. Geophys. Res., 112, D22S31, doi:10.1029/2006JD008120, 2007.

Takiguchi, Y., Takami, A., Sadanaga, Y., Lun, X., Shimizu, A., Matsui, I., Sugimoto, N., Wang, W., Bandow, H., and Hatakeyama, S.: Transport and transformation of total reactive nitrogen over the East China Sea, J. Geophys. Res., 113, D10306, doi:10.1029/2007JD009462, 2008.

Walcek, C. J. and Aleksic, N. M.: A simple but accuate mass conservative peak-preserving, mixing ratio bounded advection algorithm with fortran code, Atmos. Environ., 32, 3863-3880, 1998.
Walcek, C. J. and Teylor, G. R.: A theoretical method for computing vertical distributions of acidity and sulfate production within cumulus clouds, J. Atmos. Sci., 43, 339-355, 1986.

Wang, Z., Akimoto, H., and Uno, I.: Neutralization of soil aerosol and its impact on the distribution of acid rain over east Asia: Observations and model results, J. Geophys. Res., 107, 4389, doi:10.1029/2001JD001040, 2002.

Whitby, E. R. and McMurry, P. H.: Modal aerosol dynamics modeling, Aerosol Sci. Technol., 27, 673-688, 1997.

Yang, W., Shabanov, N. V., Huang, D., Wang, W., Dickinson, R. E., Nemani, R. R., Knyazikhin, Y., and Myneni, R. B.: Analysis of leaf area index products from combination of MODIS Terra and Aqua data, Remote Sens. Environ., 104, 297-312, 2006.

Yumimoto, K., Uno, I., Sugimoto, N., Shimizu, A., Liu, Z., and Winker, D. M.: Adjoint inversion modeling of Asian dust emission using lidar observations, Atmos. Chem. Phys., 8, 2869 2884, doi:10.5194/acp-8-2869-2008, 2008.

Zhang, L., Gong, S., Padro, J., and Barrie, L.: A size-segregated particle dry deposition scheme for an atmospheric aerosol module, Atmos. Environ., 35, 549-560, 2001.

Zhang, L., Brook, J. R., and Vet, R.: A revised parameterization for gaseous dry deposition in air-quality models, Atmos. Chem. Phys., 3, 2067-2082, doi:10.5194/acp-3-2067-2003, 2003.

Zhang, Q., Streets, D. G., Carmichael, G. R., He, K. B., Huo, H., Kannari, A., Klimont, Z., Park, I. S., Reddy, S., Fu, J. S., Chen, D., Duan, L., Lei, Y., Wang, L. T., and Yao, Z. L.: Asian emissions in 2006 for the NASA INTEX-B mission, Atmos. Chem Phys., 9, 5131-5153, doi:10.5194/acp-9-5131-2009, 2009.

Zhang, Y., McMurry, P. H., Yu, F., and Jacobson, M. Z.: A comparative study of nucleation parameterizations: 1 . Examination and evaluation of the formulations, J. Geophys. Res., 115, D20212, doi:10.1029/2010JD014150, 2010.

Zhu, A., Ramanathan, V., Li, F., and Kim, D.: Dust plumes over the Pacific, Indian and Atlantic Oceans: Climatology and radiative impact, J. Geophys. Res., 112, D16208, doi:10.1029/2007JD008427, 2007. 